\title{
MOLECULAR GEOMETRY, VIBRATIONAL SPECTROSCOPIC, MOLECULAR ORBITAL AND MULLIKEN CHARGE ANALYSIS OF 4-(CARBOXYAMINO)- BENZOIC ACID: MOLECULAR DOCKING AND DFT CALCULATIONS
}

\author{
S.N.Saravanamoorthy*, B. Vasanthi, R. Poornima \\ Department of Physics, Devanga Arts College, Aruppukottai, Tamil Nadu, India. \\ *Corresponding author: snsaravanamoorthy@gmail.com
}

\begin{abstract}
Structure based biological and chemical properties of 4-(carboxyamino)-benzoic acid has been studied by quantum chemical methods. The revamped geometric structure and its quantum chemical parameters were obtained by DFT-B3LYP/6-311G method. Normal mode analysis is performed to assign the fundamental vibrational frequencies as per the potential energy distribution (PED) by using the VEDA program. Simulation of IR and Raman spectral patterns are observed by refinement of scale factors. TD-DFT approach is used to explore the excited states of molecule and prediction of electronic absorption spectra. NMR chemical shifts of the molecule are determined by the gauge independent atomic orbital method. The molecular docking is performed to recognize the binding energy of the ligand with the dynamic site of protein. In our docking analysis, the protein 5DT6 shows the best results than other three proteins which could be used for further analysis. Further inter and intra molecular interactions, electrophilic, nucleophilic and chemical reactivity sites are found by molecular electrostatic potential, HOMO-LUMO and Global chemical reactivity descriptors. Thermodynamic property of the title compound is also reported. The determined quantum chemical parameters show high reactivity and the dipole moment was sufficiently high enough to induce nonlinear characteristics which are required for applications in optoelectronic devices.
\end{abstract}

Keywords: DFT, HOMO, LUMO, MEP, FMO, RDG, ADMET

\section{INTRODUCTION}

p-Aminobenzoic acid (PABA) shows very important roles in a wide variety of metabolic processes. PABA, a benzene ring with para (carbon 1 and 4) places of amine and carboxylic acid gatherings, is a zwitterion. PABA is a flexible reagent for structure expansion through direct hydrogen holding relationship, through both the carboxylic and amine utilitarian gatherings. The interest in carboxylate builds all in all and a benzoic acid subsidiary 
specifically keeps on developing as a result of their substance and natural properties. Benzoic acids and their subordinates are significant underlying components for some, regular items, being engaged with different physiological cycles in plants. Among these accumulates, PABA has shown organic, therapeutic and modern interest. PABA is a notable compound of high biological importance and it is present in plant and animal tissues and also sometimes referred to as bacterial vitamin $\mathrm{H}_{1}, \mathrm{~B}_{\mathrm{x}}$ or $\mathrm{B}_{10}$ [1]. PABA is a well-known forerunner of folic acid [2], and has as of late been recognized as a coenzyme Q precursor [3,4], which opens new possibilities for its application in medicine. It is a structure block utilized in plan of medications and as often as possible found as a design moiety in drugs [5]. PABA displays a wide scope of restorative uses as cell reinforcement [6,7], antibacterial [8,9], antimutagenic [10], anticoagulant [11,12], fibrinolytic and immunomodulating specialist [13], defensive medication against UV-illumination [14-16] and in indicative tests for the condition of the gastrointestinal tract $[17,18]$. Late investigations in agribusiness report the part of PABA in plant thermotolerance [19] and its activity as compound inducer of foundational obtained obstruction against plant microorganisms [20]. Viewed as in the B-complex nutrient family and described by security and cost adequacy, PABA is oftentimes added alongside plant chemicals in nutriment media as a trigger of seed germination [21].

Due to the interest in the field of new materials, the chemical structures of organic-inorganic hybrid materials have been extensively investigated. The knowledge of binding energy and energy band gap explains the intrinsic properties like chemical reactivity and electrophilic sites of the compound predicted from quantum chemical calculations. To the best of our knowledge, no detailed quantum chemistry study has been performed for 4-(carboxyamino)benzoic acid. The optimized structure and its geometric parameters are also found. The vibrational studies for each functional group are studied in detail using VEDA4 program. The nonlinear optical materials have potential applications in areas like optical limiting, signal processing, optical logic gates, laser radiation protection, etc. [22-24]. In addition to these properties, UV spectra, and thermodynamic properties are also examined for the compound. The suitable computational calculation of DFT has been performed with the help of Gaussian 09W package and the results obtained in the theoretical technique were evaluated.

\section{MATERIAL AND METHODS}

The three dimensional atomic design of the title compound for theoretical computational work was downloaded from PubChem site. Every one of the computations was performed on Gaussian 09W programming with DFT method. For direct molecular structure implementation to compute vibrational spectra, DFT-B3LYP/6-311G technique was utilized. 
The molecular geometry and vibrational frequencies values of the molecule for title compound in ground state have been determined.

\section{RESULTS AND DISCUSSION}

\subsection{Geometrical structure}

The optimized molecular structure of 4-(carboxyamino)-benzoic acid is shown in Figure 1. The molecular geometry of the title compound is explained in terms of bond lengths, bond angles and dihedral angles. In carboxyamino group, the $\mathrm{C}-\mathrm{N}$ bond distance are C6-N5 $=1.395$ $\AA$ and $\mathrm{C} 13-\mathrm{N} 5=1.3898 \AA$. The bond length of N5-H18 and O1-H19 are found at $1.0173 \AA$ and $0.9809 \AA$ respectively. The shortest and medium $\mathrm{C}-\mathrm{O}$ bond distances are observed at $1.2354 \AA(\mathrm{C} 12-\mathrm{O} 2)$ and $1.3614 \AA$ (C12-O1). Alcolea Palafox M et.al., [25] reported the corresponding values for phenyl ring atoms $(\mathrm{C}-\mathrm{C})$ in the monomer form varies from $1.392 \AA$ to $1.402 \AA$. C-C bond lengths varies at B3LYP level in monomer form from $1.3948 \AA$ (for C10-C8, C6-C8, C6-C9, C11-C9, C7-C11) to $1.4543 \AA$ (for C7-C12). And also an endocyclic $\mathrm{C}-\mathrm{C}-\mathrm{C}$ bond angle varies from $119.9^{\circ}$ to $120^{\circ}$. For the title compound, totally two $\mathrm{C}-\mathrm{N}-\mathrm{H}$ bonds are appeared. The DFT calculations give the bond angles C6-N5-H18 $=115.9^{\circ}$ and C13-N5-H18 $=115.7^{\circ}$. The carboxyamino and phenyl ring are joined with C6-N5-C13 bond. It makes an angle of $128.37^{\circ}$. The dihedral angle of phenyl group attached to the carboxyamino group ranges from $-179.9^{\circ}$ to $+179.9^{\circ}$.

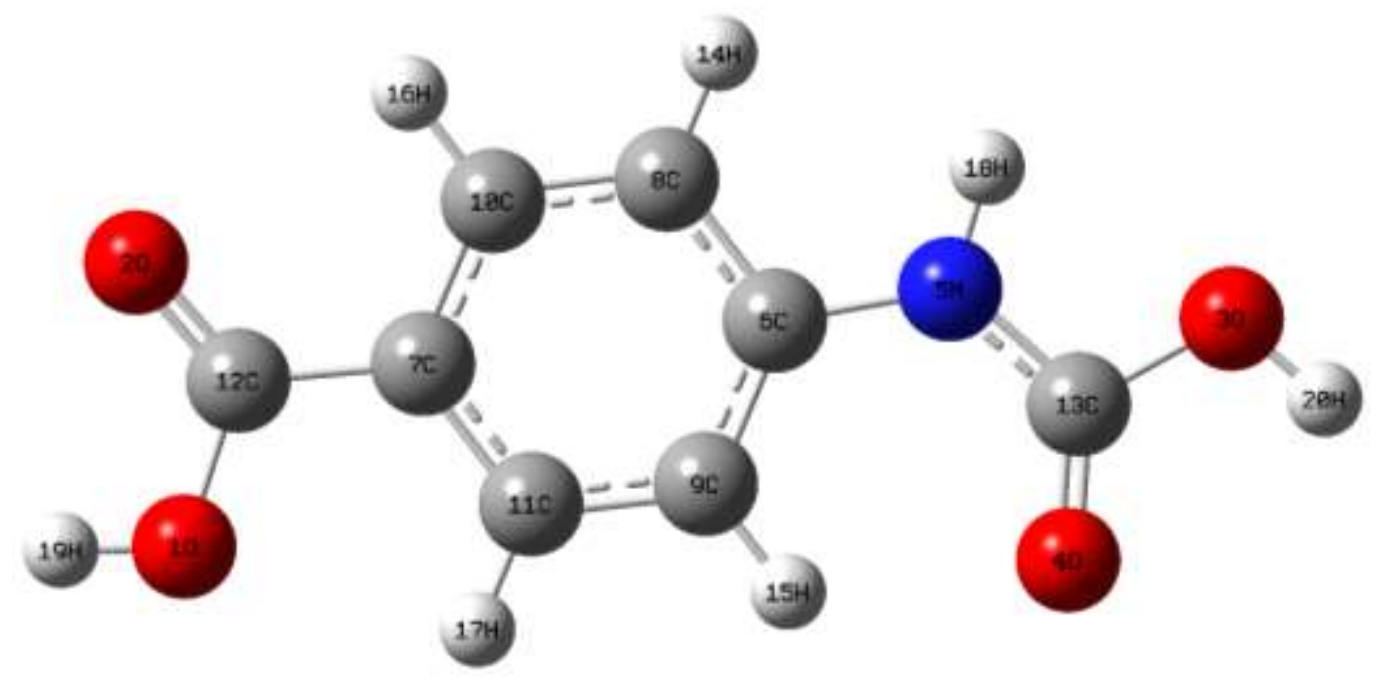

Fig. 1: The optimized molecular structure of 4-(carboxyamino)-benzoic acid

\subsection{Spectral Analysis}

The molecule 4-(carboxyamino)-benzoic acid have 20 molecules with 54 normal modes of fundamental vibration. IR and Raman spectra of the title compound are shown in Figure 2 and 3. All the normal modes of the vibrations are assigned based on the potential energy 
distribution (PED) values computed using VEDA4 program and also in comparison with the literature. The theoretical frequencies are presented in Table 1. The absorption through DFT method at $3491 \mathrm{~cm}^{-1}$ is assigned to N-H symmetry stretching mode and $3499 \mathrm{~cm}^{-1}$ is obtained in HF method. Wang and Ma [26] suggested N-H stretching bands in the region, 3365-3374 $\mathrm{cm}^{-1}$. Generally the aromatic C-H stretching vibration appears weakly between $3120-3000 \mathrm{~cm}^{-}$ ${ }^{1}$. But in B3LYP calculations, it gives band in the range $3058-3133 \mathrm{~cm}^{-1}$. It shows that symmetry stretching mode is active. These four modes are pure stretching modes as is evident from PED column; they almost contribute 95\%. The in-plane $\mathrm{C}-\mathrm{H}$ bending vibrations normally appear in the range $1000-1300 \mathrm{~cm}^{-1}$ in the substituted benzenes and the out-of-plane bending vibrations occur in the region $750-1000 \mathrm{~cm}^{-1}$ region [27,28]. In aromatic compounds, the C-N stretching vibration usually appears in the region $1400-1200 \mathrm{~cm}^{-1}$. The absorption band located at $1331 \mathrm{~cm}^{-1}$ is attributed to $\mathrm{C}-\mathrm{N}$ stretching vibration. An asymmetric stretching mode of $\mathrm{C}-\mathrm{N}$ band appears at $1246 \mathrm{~cm}^{-1}$. Usually, $\mathrm{C}=\mathrm{N}$ stretching bands appears in the region $1598-1638 \mathrm{~cm}^{-1}$ [26]. In the present study, the $\mathrm{C}=\mathrm{N}$ stretching mode is observed at $1623 \mathrm{~cm}^{-1}$ for HF method. The absorption is touchy for both the carbon and oxygen particles of the carbonyl gathering. Both have the same while it vibrates. Normally, the C-O stretching vibrations occur in the region $1260-1000 \mathrm{~cm}^{-1}$ [29]. In the present study, the C-O stretching vibration is assigned at $1314 \mathrm{~cm}^{-1}$ at B3LYP/6-311G level. The assignments of the COO group vibrations are closely agree with the literature values [30,31]. The in-plane COO bending vibration is localized at $839 \mathrm{~cm}^{-1}$. A very weak COO out-of bending mode is found at $684 \mathrm{~cm}^{-1}$. The band observed at 960, 871 and $839 \mathrm{~cm}^{-1}$ was assigned to C-C-C stretching vibrations in DFT method. The $\mathrm{O}-\mathrm{H}$ stretching vibrations are touchy to hydrogen bonding. The hydrogen bonding alters the frequencies of the stretching and bending vibration. The hydrogen bonding if present in five or six member ring system would reduce the $\mathrm{O}-\mathrm{H}$ stretching band to $3200-3550 \mathrm{~cm}^{-1}$ region [32]. In the computed IR spectrum, a weak band observed at 3573 and $3538 \mathrm{~cm}^{-1}$ are assigned to $\mathrm{O}-\mathrm{H}$ stretching mode of vibration. The potential energy distribution contribution to these modes is $100 \%$. 


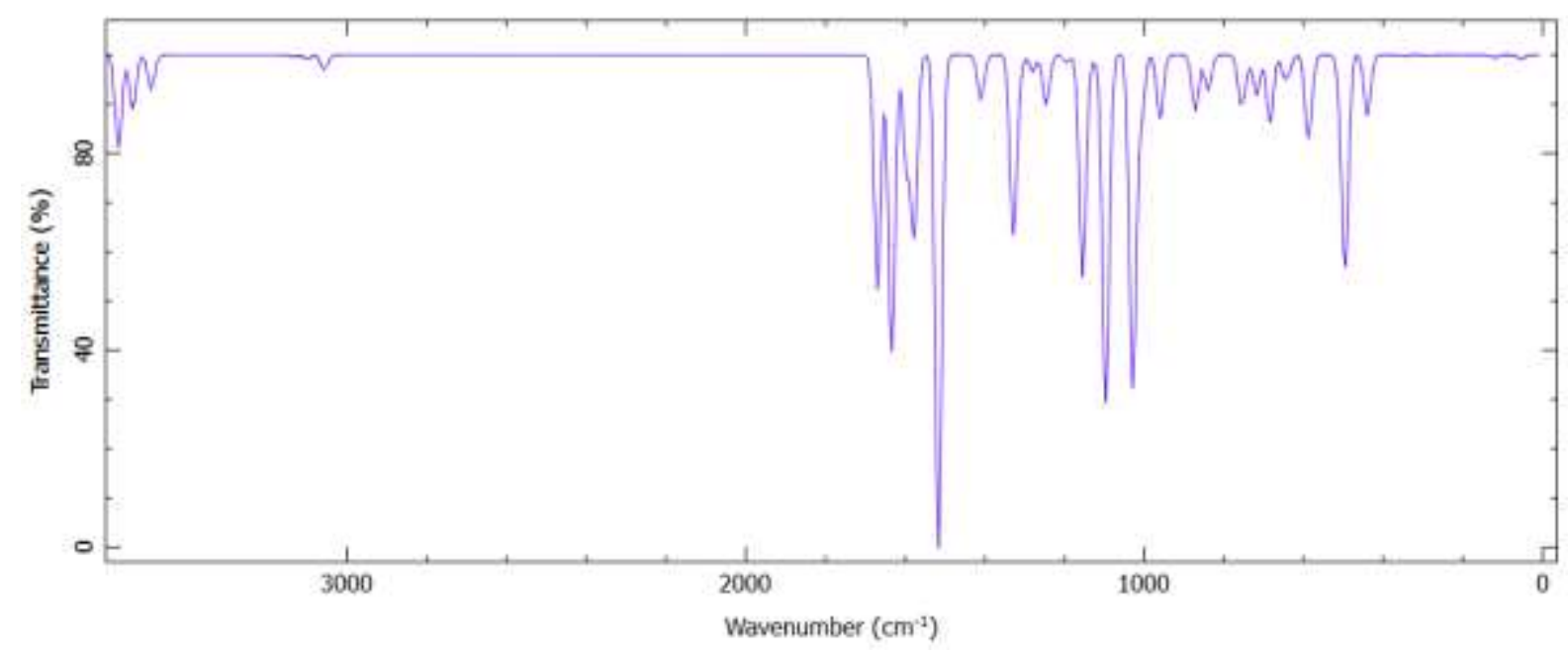

Fig. 2: Computed FT-IR spectra for 4-(carboxyamino)-benzoic acid using DFT-B3LYP/6-311G method

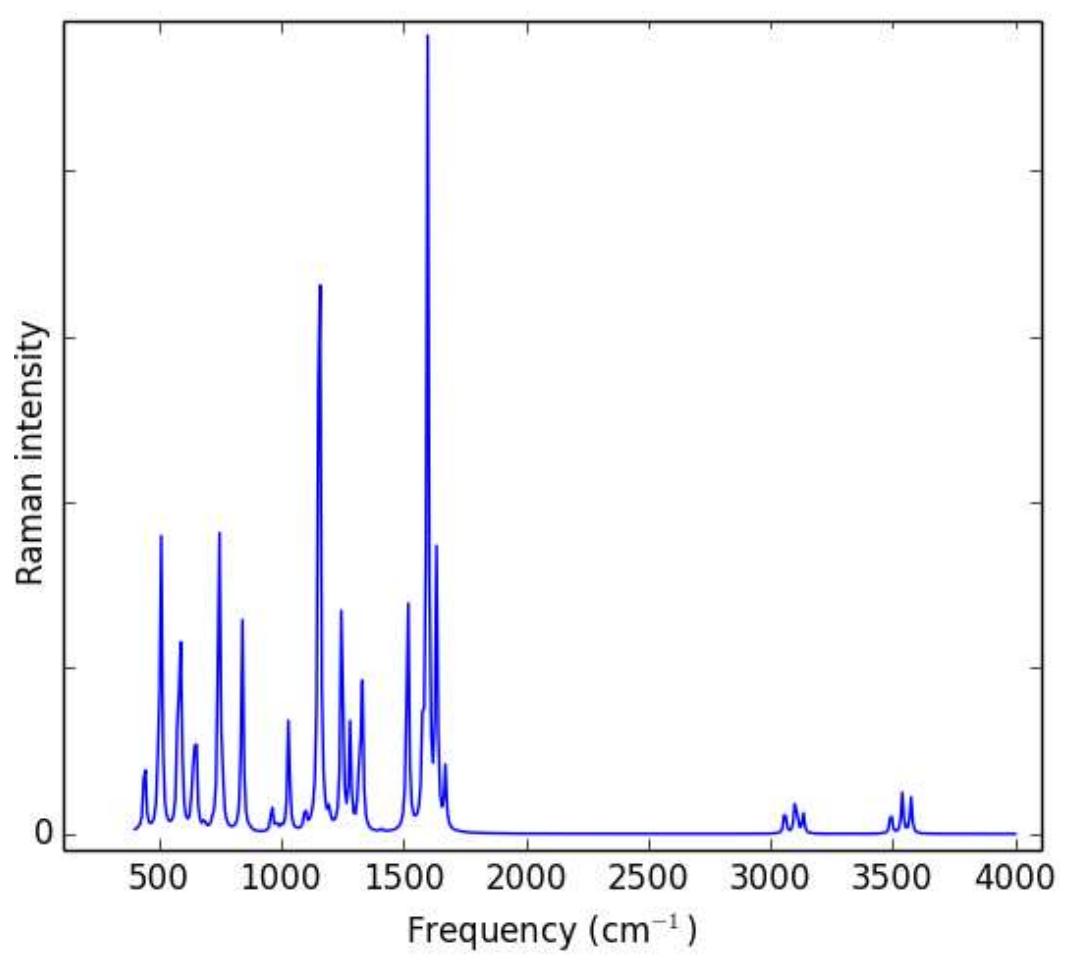

Fig. 3: Computed Raman spectra for 4-(carboxyamino)-benzoic acid using DFT-B3LYP/6-311G method

Table 1: Calculated vibrational frequencies of 4-(carboxyamino)-benzoic acid

\begin{tabular}{|c|c|c|c|c|c|c|}
\hline \multirow{2}{*}{ Mode } & \multirow{2}{*}{$\begin{array}{c}\text { Symmetry } \\
\text { Species } \\
\text { Cs }\end{array}$} & \multicolumn{4}{|c|}{ Theoretical Wavenumbers $\left(\mathbf{c m}^{-\mathbf{1}}\right)$} & \multirow{2}{*}{$\begin{array}{c}\text { Vibrational } \\
\text { Assignments } \\
\text { (\%PED) }\end{array}$} \\
\cline { 3 - 6 } & & DFT B3LYP/6-311G & \multicolumn{2}{|c|}{ HF/6-31G } & \\
\cline { 3 - 6 } & Unscaled & Scaled & Unscaled & Scaled & \\
\hline 1 & A & 50.65 & 48.93 & 50.72 & 45.79 & tHOCN(81) \\
\hline 2 & A & 62.31 & 60.19 & 69.52 & 62.77 & OUT CCCC(53) \\
\hline
\end{tabular}




\begin{tabular}{|c|c|c|c|c|c|c|}
\hline 3 & A & 83.23 & 80.39 & 88.16 & 79.60 & ఒHNCO(80) \\
\hline 4 & A & 124.06 & 119.84 & 135.65 & 122.49 & 七CCCC(65) \\
\hline 5 & A & 148.77 & 143.70 & 167.80 & 151.52 & OUT CCCC(68) \\
\hline 6 & A & 216.87 & 209.50 & 236.41 & 213.47 & זCCNC(70) \\
\hline 7 & A & 288.11 & 278.31 & 310.88 & 280.72 & $\mathrm{\tau CCCO}(81)$ \\
\hline 8 & A & 311.06 & 300.48 & 345.46 & 311.94 & 七HOCN(80) \\
\hline 9 & A & 361.02 & 348.74 & 391.27 & 353.31 & זCCCC(62) \\
\hline 10 & A & 432.32 & 417.61 & 476.33 & 430.12 & זCCCC(64) \\
\hline 11 & A & 455.56 & 440.06 & 496.82 & 448.62 & 七HCCC(77) \\
\hline 12 & A & 511.48 & 494.09 & 556.71 & 502.70 & тHCCC(63) \\
\hline 13 & A & 512.57 & 495.14 & 573.25 & 517.64 & นHCCC(73) \\
\hline 14 & A & 524.97 & 507.12 & 584.90 & 528.16 & זHCCC(75) \\
\hline 15 & A & 597.12 & 576.81 & 641.01 & 578.83 & זHNCO(81) \\
\hline 16 & A & 609.32 & 588.60 & 660.89 & 596.78 & OUT CCCC(76) \\
\hline 17 & A & 658.54 & 636.15 & 716.09 & 646.63 & тHOCC(85) \\
\hline 18 & A & 668.59 & 645.85 & 730.15 & 659.32 & $\beta C N C(77)$ \\
\hline 10 & A & 672.21 & 649.35 & 739.17 & 667.47 & $\beta C N C(35)$ \\
\hline 20 & A & 708.58 & 684.48 & 789.00 & 712.46 & $\gamma \mathrm{CCO}(61)$ \\
\hline 21 & A & 743.06 & 717.79 & 842.89 & 761.13 & $\beta C N C(77)$ \\
\hline 22 & A & 770.52 & 744.32 & 861.31 & 777.75 & $\beta C N C(69)$ \\
\hline 23 & A & 783.96 & 757.30 & 892.13 & 805.59 & $\beta C C N(71)$ \\
\hline 24 & A & 868.99 & 839.44 & 943.99 & 852.42 & $\beta C C C(61)$ \\
\hline 25 & A & 869.10 & 839.54 & 982.60 & 887.29 & $\beta O C O(68)$ \\
\hline 26 & A & 902.28 & 871.60 & 1024.39 & 925.02 & $\gamma \mathrm{CCC}(51)$ \\
\hline 27 & A & 993.92 & 960.12 & 1110.49 & 1002.77 & $\beta C C C$ (38) \\
\hline 28 & A & 1015.09 & 980.57 & 1135.91 & 1025.73 & $\beta \mathrm{HCC}(57)$ \\
\hline 29 & A & 1033.43 & 998.29 & 1168.26 & 1054.94 & $\gamma \mathrm{HCC}(49)$ \\
\hline 30 & A & 1042.89 & 1007.43 & 1187.20 & 1072.04 & $\beta \mathrm{HCC}(28)$ \\
\hline 31 & A & 1065.09 & 1028.87 & 1201.83 & 1085.25 & $\gamma \mathrm{HCC}(50)$ \\
\hline 32 & A & 1134.98 & 1096.38 & 1256.78 & 1134.87 & $\beta \mathrm{HNC}(27)$ \\
\hline 33 & A & 1163.23 & 1123.67 & 1267.00 & 1144.10 & $\beta \mathrm{HOC}(40)$ \\
\hline 34 & A & 1195.04 & 1154.40 & 1297.94 & 1172.04 & $\beta \mathrm{HOC}(33)$ \\
\hline 35 & A & 1236.99 & 1194.92 & 1341.73 & 1211.58 & $\beta C C C$ (73) \\
\hline
\end{tabular}




\begin{tabular}{|c|c|c|c|c|c|c|}
\hline 36 & A & 1290.10 & 1246.23 & 1353.80 & 1222.48 & $\alpha \mathrm{NC}(36)$ \\
\hline 37 & A & 1325.19 & 1280.13 & 1422.95 & 1284.93 & $\mathrm{vCC}(44)$ \\
\hline 38 & A & 1361.12 & 1314.83 & 1465.49 & 1323.33 & vOC(70) \\
\hline 39 & A & 1375.35 & 1328.58 & 1502.96 & 1357.17 & vCC(39) \\
\hline 40 & A & 1378.52 & 1331.65 & 1511.58 & 1364.95 & vNC(63) \\
\hline 41 & A & 1459.59 & 1409.96 & 1591.84 & 1437.44 & vCC(59) \\
\hline 42 & A & 1558.47 & 1505.48 & 1702.83 & 1537.66 & vCC (47) \\
\hline 43 & A & 1569.61 & 1516.24 & 1729.04 & 1561.33 & $v C C(28)$ \\
\hline 44 & A & 1632.62 & 1577.11 & 1797.91 & 1623.51 & $\mathrm{vNC}(30)$ \\
\hline 45 & A & 1653.52 & 1597.29 & 1817.38 & 1641.10 & $\alpha \mathrm{CC}(33)$ \\
\hline 46 & A & 1691.09 & 1633.58 & 1887.95 & 1704.82 & vOC(73) \\
\hline 47 & A & 1728.13 & 1669.37 & 1898.80 & 1714.62 & $\mathrm{vCC}(29)$ \\
\hline 48 & A & 3165.96 & 3058.31 & 3361.97 & 3035.86 & $\mathrm{vCH}(91)$ \\
\hline 49 & A & 3207.52 & 3098.46 & 3405.66 & 3075.31 & $\mathrm{vCH}(95)$ \\
\hline 50 & A & 3217.69 & 3108.28 & 3414.41 & 3083.21 & $\mathrm{vCH}(91)$ \\
\hline 51 & A & 3244.09 & 3133.78 & 3454.93 & 3119.8 & $\mathrm{vCH}(95)$ \\
\hline 52 & A & 3614.53 & 3491.63 & 3875.66 & 3499.72 & $\mathrm{vNH}(100)$ \\
\hline 53 & A & 3662.73 & 3538.19 & 4003.83 & 3615.46 & $\mathrm{vOH}(100)$ \\
\hline 54 & A & 3699.58 & 3573.79 & 4025.91 & 3635.40 & $\mathrm{vOH}(100)$ \\
\hline
\end{tabular}

Abbreviations: $v-$ stretching vibrations; $\alpha$ - asymmetric stretching; $\tau-$ torsion; $\beta$ - in plane bending vibrations; $\gamma$ - out of plane bending

\subsection{UV spectral analysis}

The UV spectral analysis represents that the electron absorption corresponds to the transition from the ground state to the first excited state [33]. The band gap energy was calculated using the formula $\mathrm{E}=\mathrm{hc} / \lambda$, where $\mathrm{h}$ and $\mathrm{c}$ are constants, $\lambda$ is the cut-off wavelength. The theoretical excitation energies, absorption wavelength and oscillator strength are summarized in Table 2. The UV spectrum of the title compound is shown in Figure 4. Energy gap were determined at the B3LYP/6-311G level utilizing TD-DFT approach in gas phase. These transitions are based totally on the groundwork of fundamental contribution of molecular orbitals. The orbitals contributions $\leq 10 \%$ are neglected [34]. In this case, the strong transition was observed at $281 \mathrm{~nm}$ with maximum oscillator strength $\mathrm{f}=0.6462$ with $4.41 \mathrm{eV}$ energy gap and from HOMO-LUMO diagram is $5 \mathrm{eV}$. The other transitions are found at 258, $272 \mathrm{~nm}$. UV visible spectra show that entire transitions belong to the quarts ultraviolet region (240-340 
$\mathrm{nm})$. So the compound can be used for quarts optics [33]. The peak was observed at $281 \mathrm{~nm}$ which was due to the presence of two $\pi$ conjugated system of bonds $(C=N, C=O)$ in the compound. It was evidence that the present compound is able to produce the optical energy with second and third fold frequency. The group contributions to the molecular orbital and the density of state (DOS) are found using Gauss-sum 2.2 program [35]. The calculated TDOS diagram of the title molecule is shown in Figure 5. The DOS spectra were created by convoluting the molecular orbital information with Gaussian cures of unit height [36].

Table 2: The theoretical excitation energies, absorption wavelength and oscillator strength

\begin{tabular}{|c|c|c|c|}
\hline$\lambda \max (\mathbf{n m})$ & Band gap $(\mathbf{e V})$ & Energy $\left(\mathbf{c m}^{-\mathbf{1}}\right)$ & $\mathbf{f}$ \\
\hline 258 & 4.81 & 38682.61 & 0.543 \\
\hline 272 & 4.56 & 36722.67 & 0.612 \\
\hline 281 & 4.41 & 35538.64 & 0.6462 \\
\hline
\end{tabular}

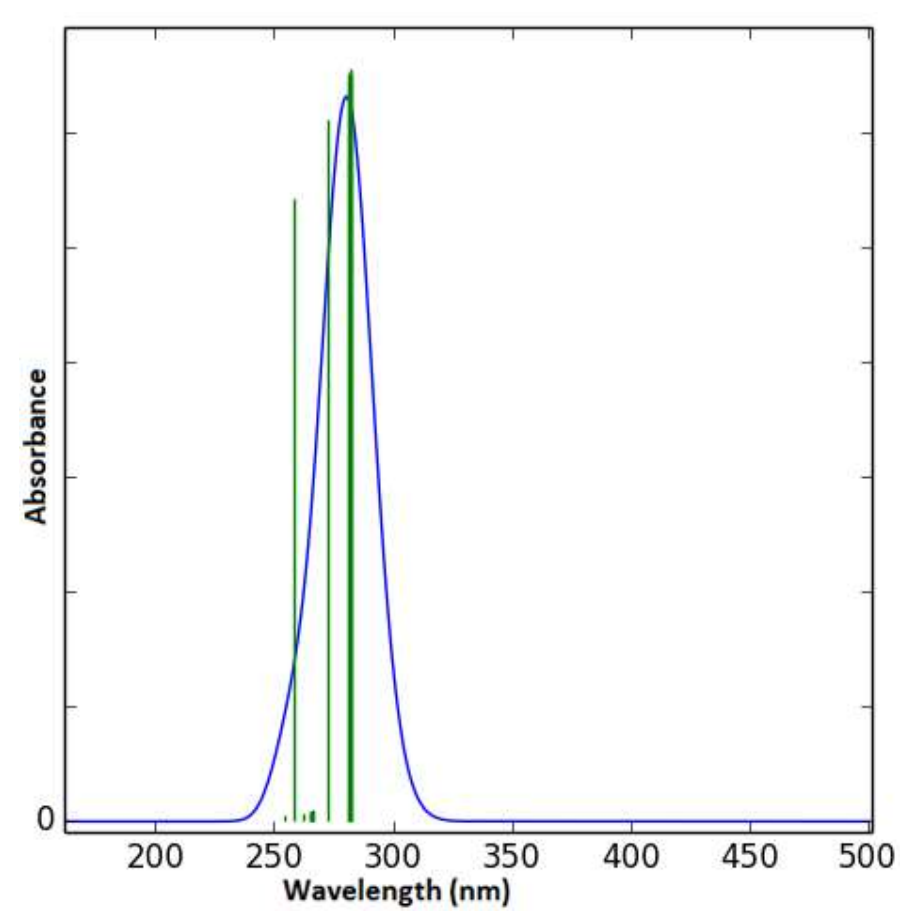

Fig. 4: The UV spectrum of the title compound 


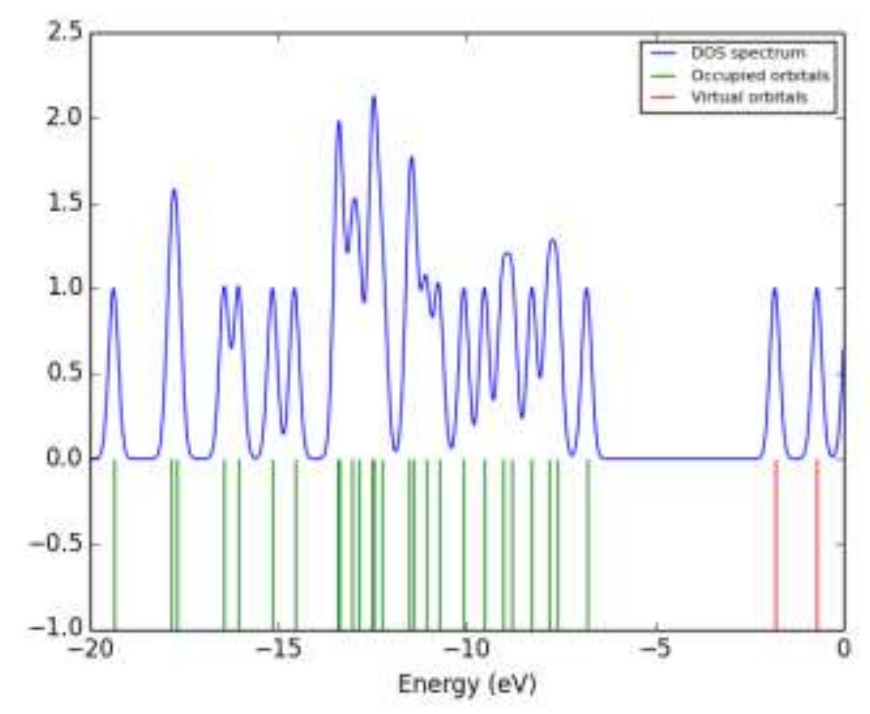

Fig. 5: The calculated TDOS diagram

\subsection{NMR assessment}

The DFT shielding calculations are fast, accurate and significant technique for structural determination of the carbon-hydrogen framework of organic compounds [37]. The chemical shifts for ${ }^{1} \mathrm{H}$ and ${ }^{13} \mathrm{C}$ atoms of the compound are calculated for optimized structure, supported by gauge including atomic orbital (GIAO) method using B3LYP functional with 6-311G basis set. The graphical representations of computed values are proven in Figure 6 and 7. Because of the distinctive idea of adjoining molecules and encompassing electrons, every core in the compound is synthetically inconsistent to another. So, NMR signals resonate for chemically unequal nuclei at various ppm values. The carbonyl carbons C12 and C13 are attached to two oxygen atoms and hence it is low deshielded than all other carbon atoms. Its chemical shift values for C15 and C17 were observed at 14.34 and 29.42 ppm respectively. C12 is much deshielded than all the other carbon atoms. The $\mathrm{C} 7$ carbon atom is more deshielded due to its connection with carbonyl carbon atom. Their computed values occurred at $64.41 \mathrm{ppm}$. The large values of $\mathrm{C} 13$ and $\mathrm{C} 7$ indicate that the large magnitude of the charges associated with these atoms, through the first one is highly positive and latter is highly negative. The chemical shifts of the carbon atoms, namely C8, C9, C10 and C11, almost lie in the same range, from $48.25 \mathrm{ppm}$ to $71.5 \mathrm{ppm}$. Figure 7 clearly indicates that the chemical shift values of the hydrogen atoms are observed almost equal around $30 \mathrm{ppm}$, which shows that the chemical environment of hydrogen atoms is affected by oxygen, nitrogen or any carbon atoms. This is because of the theoretical calculations carried out in the isolated gaseous phase of the theoretical chemical conversion assay. The signals of aromatic protons were observed at $24.07-27.26 \mathrm{ppm}$. The obtained results are found to be in good agreement with other 
investigators [38]. The theoretically calculated chemical shift of N5 was observed at 135.39 ppm. In addition, four oxygen peaks of $\mathrm{O} 1, \mathrm{O} 2, \mathrm{O} 3$ and $\mathrm{O} 4$ are observed at 121.6, -125.8, 137.3 and $-36.35 \mathrm{ppm}$.

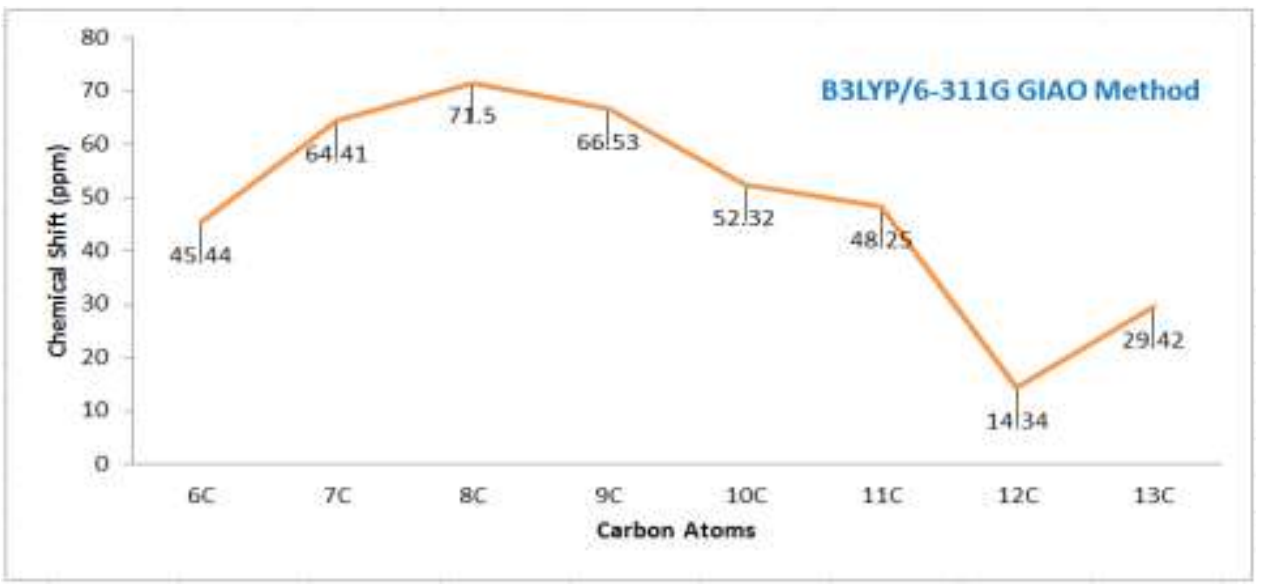

Fig. 6: The graphical representation of chemical shift value (ppm) of carbon atoms

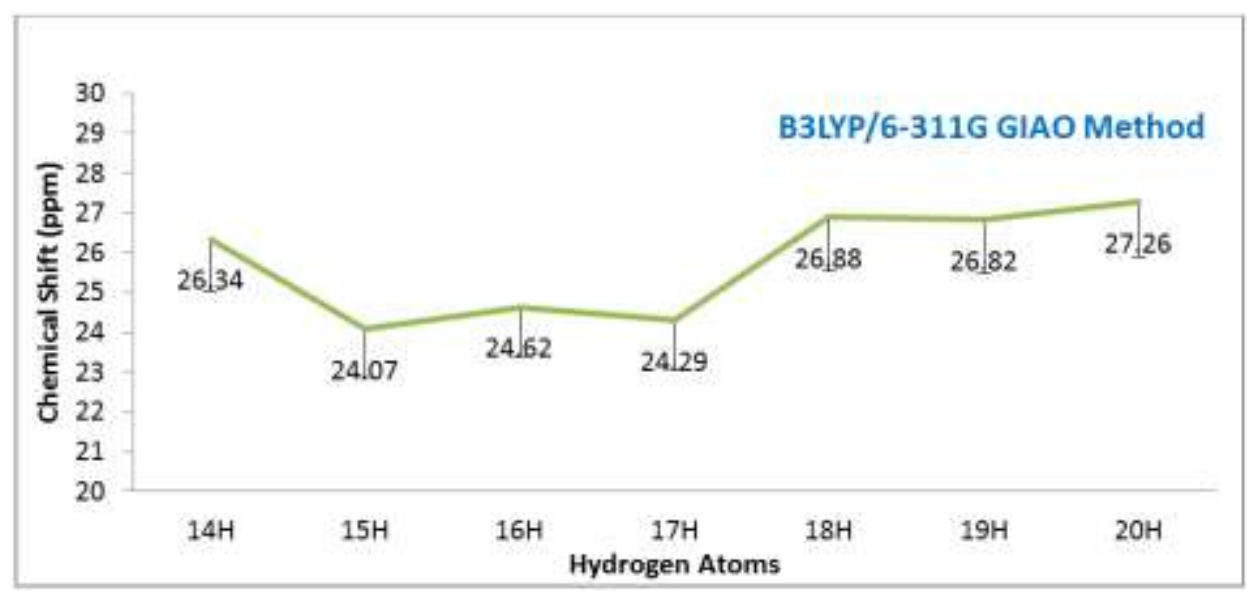

Fig. 7: The graphical representation of chemical shift value (ppm) of hydrogen atoms

\subsection{Parameters of NLO properties}

When electromagnetic fields interact with various media, it produces new fields with changes in frequency, phase, amplitude, or other characteristics of the incident fields resulting nonlinear optical (NLO) properties [39]. The total hyperpolarizability $\left(\beta_{\text {tot }}\right)$ is the significant boundary to assess the NLO susceptibility. It means that the compound with large value of $\beta_{\text {tot }}$ is predicted to be a potential NLO active one and vice versa [40]. NLO behavior of compounds can be easily perceived and understood using theoretical calculations. Therefore, a theoretical correlation between the structure of the compound and NLO property may suggest the possibilities of design and synthesis of new NLO materials. First order hyperpolarizability $(\beta)$ can be described by $3 \times 3 \times 3$ matrices. The second order 
hyperpolarizability is a fourth rank tensor. It is known as third-order NLO coefficient. The nonlinear parameters of the title compound are calculated by using DFT theory based on the finite field approach and HF method. The nonlinear parameters are reported in Table 3. The vector component $\left(\beta_{\mu}\right)$ and average second order hyperpolarizability $\langle\gamma\rangle$ are normally calculated from electronic filed induced second harmonic generation experiments and are used to compare nonlinear optical response of different compounds. The total static dipole moment $\left(\mu_{\text {tot }}\right)$, isotropic molecular polarizability $\left(\alpha^{\text {iso }}\right)$, asymmetry parameter $(\eta)$, Polarizability anisotropy $(\Delta \alpha)$, first-order hyperpolarizability $\left(\beta_{\mathrm{tot}}\right)$ and second-order hyperpolarizabilities $\langle\gamma\rangle$ are defined using the $\mathrm{x}, \mathrm{y}, \mathrm{z}$ components as [41-43].

$$
\begin{aligned}
& \mu=\left(\mu_{x}^{2}+\mu_{y}^{2}+\mu_{z}^{2}\right)^{1 / 2} \\
& \alpha^{i s o}=\left(\alpha_{x x}+\alpha_{y y}+\alpha_{z z}\right) / 3 \\
& \Delta \alpha=\left[\alpha_{x x}-\left(\alpha_{y y}+\alpha_{z z}\right) / 2\right] \\
& \eta_{\propto}=\left[\left(\alpha_{y y}-\alpha_{z z}\right) /\left(\alpha_{x x}-\alpha^{i s o}\right)\right] \\
& \beta_{t o t}=\left[\left(\beta_{x x x}+\beta_{x y y}+\beta_{x z z}\right)^{2}+\left(\beta_{y y y}+\beta_{x x y}+\beta_{y z z}\right)^{2}+\left(\beta_{z z z}+\beta_{x x z}+\beta_{y y z}\right)^{2}\right]^{1 / 2} \\
& \beta_{\mu}=\frac{\sum_{i=x, y, z} \mu_{i}\left(\beta_{i x x}+\beta_{i y y}+\beta_{i z z}\right)}{\sqrt{\mu_{x}^{2}+\mu_{y}^{2}+\mu_{z}^{2}}} \\
& \langle\gamma\rangle=\frac{1}{5}\left(\gamma_{x x x x}+\gamma_{y y y y}+\gamma_{z z z z}+2 \gamma_{x x y y}+2 \gamma_{x x z z}+2 \gamma_{y y z z}\right)
\end{aligned}
$$

For the (hyper)polarizabilities, the calculated values are in atomic units throughout the work. The atomic units have been converted into SI unit system. Conversion factors are 1 a.u. of $\alpha=$ $1.648778 \times 10^{-41} \mathrm{C}^{2} \mathrm{~m}^{2} \mathrm{~J}^{-2} ; 1$ a.u. of $\beta=3.206361 \times 10^{-53} \mathrm{C}^{3} \mathrm{~m}^{3} \mathrm{~J}^{-2}$; 1a.u. of $\gamma=6.235377 \times$ $10^{-65} \mathrm{C}^{4} \mathrm{~m}^{4} \mathrm{~J}^{-3}$. For B3LYP/6-311G, the calculated first order hyperpolarizability $\left(\beta_{\mathrm{tot}}\right)$ is $281.63 \times 10^{-53} \mathrm{C}^{3} \mathrm{~m}^{3} \mathrm{~J}^{-2}$ and average second order hyperpolarizability is $-0.7693 \times 10^{-61}$ $\mathrm{C}^{4} \mathrm{~m}^{4} \mathrm{~J}^{-3}$. Urea is the prototype molecule generally considered as a reference for the comparison of good nonlinear optical properties. The first-order static hyperpolarizablity of title molecule is two times greater than that of urea $\left(\beta_{\text {tot }}=138.365 \times 10^{-53} \mathrm{C}^{3} \mathrm{~m}^{3} \mathrm{~J}^{-2}\right)$. It shows that title molecule is good candidate as materials for applications in nonlinear optics. 
Table 3: Dipole moments, static electronic polarizabilities, first-order hyperpolarizabilities and second-order hyperpolarizabilities

\begin{tabular}{|c|c|c|c|c|c|}
\hline & $\begin{array}{c}\text { B3LYP/6-311G } \\
\text { Debye }\end{array}$ & B3LYP/6-311G (a.u.) & & $\begin{array}{c}\text { B3LYP/6-311G } \\
\text { (a.u.) }\end{array}$ \\
\hline$\mu_{\mathrm{x}}$ & 2.4071 & $\beta_{\mathrm{xxx}}$ & 78.9910 & $\gamma_{\mathrm{xxxx}}$ & -2750.5895 \\
\hline$\mu_{\mathrm{y}}$ & 0.9477 & $\beta_{\mathrm{xxy}}$ & -53.1922 & $\gamma_{\mathrm{yyy}}$ & -512.1349 \\
\hline$\mu_{\mathrm{z}}$ & 0.0007 & $\beta_{\mathrm{xyy}}$ & -4.6846 & $\gamma_{\mathrm{zzzz}}$ & -74.3812 \\
\hline$\mu_{\mathrm{total}}$ & 2.5869 & $\beta_{\mathrm{yyy}}$ & 13.1973 & $\gamma_{\mathrm{xxyy}}$ & -721.5517 \\
\hline$\alpha_{\mathrm{xx}}$ & -66.9074 & $\beta_{\mathrm{xxz}}$ & -0.0071 & $\gamma_{\mathrm{xxz}}$ & -585.4700 \\
\hline$\alpha_{\mathrm{yy}}$ & -74.2979 & $\beta_{\mathrm{xyz}}$ & 0.0029 & $\gamma_{\mathrm{yyzz}}$ & -109.1318 \\
\hline$\alpha_{\mathrm{zz}}$ & -76.7142 & $\beta_{\mathrm{yyz}}$ & 0.0056 & & -1233.88 \\
\hline$\alpha_{\mathrm{xy}}$ & 12.5758 & $\beta_{\mathrm{xzz}}$ & 2.2503 & & \\
\hline$\alpha_{\mathrm{xz}}$ & -0.0017 & $\beta_{\mathrm{yzz}}$ & -3.0654 & & \\
\hline$\alpha_{\mathrm{yz}}$ & -0.0004 & $\beta_{\mathrm{zzz}}$ & -0.0024 & & \\
\hline$\alpha^{\mathrm{iso}}$ & -72.6398 & $\beta_{\mathrm{tot}}$ & 87.835 & & \\
\hline$\Delta \alpha$ & 8.5986 & $\beta_{\mu}$ & 225.07 & & \\
\hline$\eta_{\alpha}$ & 0.4215 & & & & \\
\hline
\end{tabular}

\subsection{FMO Analysis}

According to FMO theory, HOMO and LUMO are important terms in quantum chemistry that reflect the bioactivity of compounds. The HOMO particularly donates electrons, while LUMO represents the ability to gain an electron. Thus, studies on FMO provide some useful information for physicists and chemists about the active mechanism [44]. The graphical representation of the FMOs for B3LYP/6-311G basis set is shown in Figure 8. The global reactivity descriptors like chemical potential, electronegativity, hardness, softness and electrophilicity index can be calculated using DFT. The electronic chemical potential describes the escaping tendency of electron from a stable system. According to Parr and Pearson [45], it can be calculated as $\mu=\left(\mathrm{E}_{\mathrm{HOMO}}+\mathrm{E}_{\mathrm{LUMO}}\right) / 2$. The negative value of the electronic chemical potential is called electronegativity $(\chi)$. Chemical hardness demonstrates the resistance to alteration in electron distribution and also it is correlated with the stability and reactivity of the chemical system. It is given by $\eta=$ Energy gap/2. The global electrophilicity index $(\omega)$ is measured in terms of chemical potential and hardness. It assesses the lowering of energy due to maximal electron flow between donor and acceptor [46]. Table 4 represents the calculated quantum molecular descriptors of title compound for B3LYP/6$311 \mathrm{G}$ basis set. The energy value of HOMO and LUMO are $-6.82 \mathrm{eV}$ and $-1.82 \mathrm{eV}$ respectively. The band gap energy value of the title compound was calculated as $5.0 \mathrm{eV}$, which confirms that the molecule has a stable structure. The ionization energy value indicates that the energy value of $6.82 \mathrm{eV}$ is required to remove an electron from HOMO. The lower value of electron affinity $(1.82 \mathrm{eV})$ indicates that the compound readily accepts electrons to 
form bonds. All these values demonstrate the biological activity of the title compound with different molecules. The calculated value of electrophilicity index (3.73) describes the biological activity of the compound. The values of electronegativity, global hardness, global softness and chemical potential of the title compound are $-4.32,2.5,0.4$ and 4.32 respectively.

Table 4: The calculated quantum molecular descriptors

\begin{tabular}{|c|l|c|}
\hline S.No. & \multicolumn{1}{|c|}{ Parameters (B3LYP/6-311G) } & Values \\
\hline 1 & $\mathrm{E}_{\mathrm{HOMO}}(\mathrm{a} . \mathrm{u})$ & -6.82 \\
\hline 2 & $\mathrm{E}_{\mathrm{LUMO}}(\mathrm{a} . \mathrm{u})$ & -1.82 \\
\hline 3 & IA: Ionization energy $=-\mathrm{E}_{\mathrm{HOMO}}(\mathrm{eV})$ & 6.82 \\
\hline 4 & $\mathrm{EA}_{\text {: Electron affinity }=-\mathrm{E}_{\mathrm{LUMO}}(\mathrm{eV})}$ & 1.82 \\
\hline 5 & $\mathrm{E}_{\mathrm{g}: \text { Energy gap }=\mathrm{E}_{\mathrm{HOMO}}-\mathrm{E}_{\mathrm{LUMO}}(\mathrm{eV})}$ & 5.0 \\
\hline 6 & $\eta:$ Hardness $=$ Energy gap $/ 2(\mathrm{eV})$ & 2.5 \\
\hline 7 & $\begin{array}{c}\mu: \text { Electronic chemical potential } \\
=\left(\mathrm{E}_{\mathrm{HOMO}}+\mathrm{E}_{\mathrm{LUMO}}\right) / 2(\mathrm{eV})\end{array}$ & -4.32 \\
\hline 8 & $\omega:$ Electrophilicity index $=\mu^{2} / 2 \eta$ & 3.73 \\
\hline 9 & $\mathrm{~S}:$ softness $=(1 / \eta)$ & 0.4 \\
\hline 10 & $\chi:$ Electro negativity $=-\mu$ & -4.32 \\
\hline 11 & $\Delta \mathrm{N}_{\max }=-\mu / \eta$ & -1.72 \\
\hline
\end{tabular}

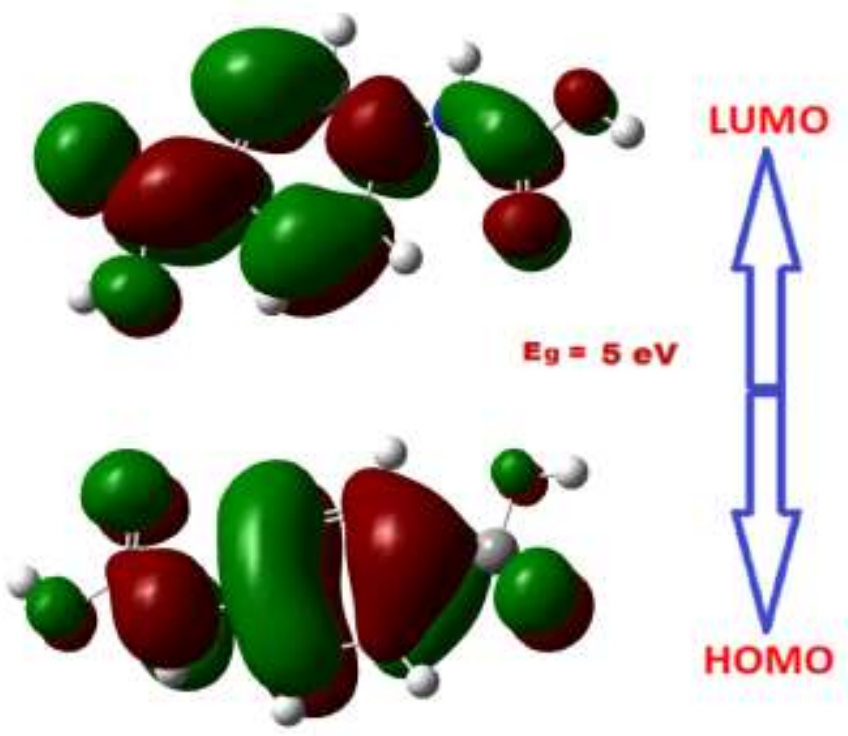

Fig. 8: The graphical representation of the FMOs

\subsection{Molecular electrostatic potential Analysis}

Molecular electrostatic potential (MEP) is important to characterise inter and intra molecular electrostatic interactions [47]. The charge spreads over the surface can be used to determine the interaction of nonlinear active molecules as well as to determine the type of chemical bond [48]. MEP is essential in structural biology to determine ligand-substrate interactions, drug-receptor and enzyme-substrate interactions [49]. To predict reactive molecular sites, the 
3D map of the molecular electrostatic potential (MEP) surface was plotted for the total electron density of the title compound and is shown in Figure 9. The electrostatic potential contour surface of the title molecule is presented in Figure 10. The different values of the electrostatic potential at 3D map are mentioned by different colours. In Gauss View, the colour code in 3D map varies between -7.113 a.u. and +7.113 a.u. The red colour region (negative electrostatic potential) is related to electrophilic attack while the blue colour region (positive electrostatic potential) represents nucleophilic attack [50]. It has been revealed through Figure 10 that there are four possible sites for electrophilic attack. As can be seen from the Figure, the negative region is mainly localised over oxygen atom. It is the most propitious site for electrophilic attack having the values -0.02 a.u. to -0.05 a.u. The nucleophilic attacks are around the hydrogen atoms with values in the range 0.05 to 0.0634 a.u. The maximum positive value 0.0634 a.u corresponds to the hydrogen atom (H20) of carboxyl group attached with Oxygen (O3).

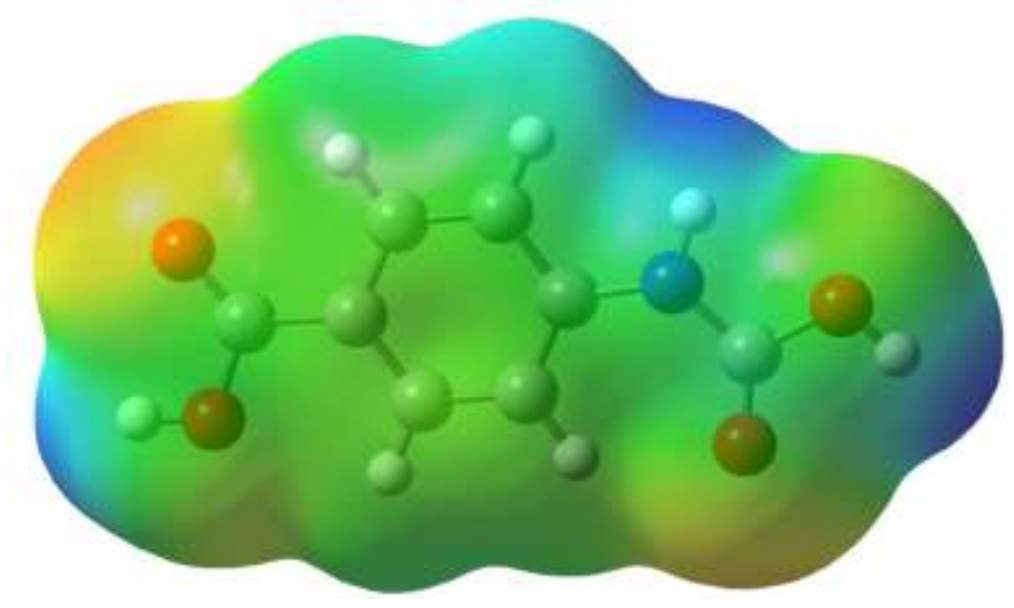

Fig. 9: 3D map of the molecular electrostatic potential (MEP)

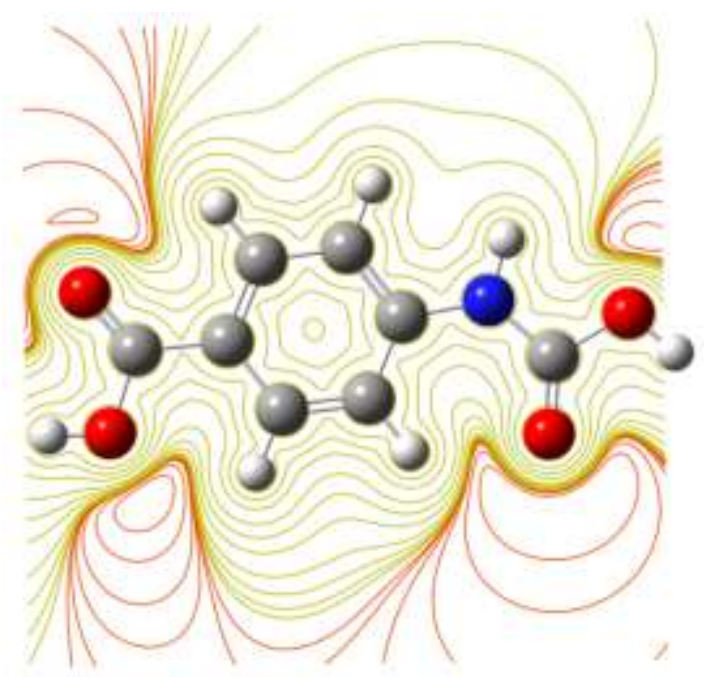

Fig. 10: The electrostatic potential contour surface of the title molecule 


\subsection{Mulliken atomic charges}

The Mulliken atomic charge is directly related to the vibrational properties of the molecule and chemical bonds present in it. And also it shows that improved numerical stability and portrays the distribution of electrons in a better way [51]. Mulliken atomic charges affect the dipole moment, polarizability, electronic structure and more properties of molecular system [52]. Figure 11 represents the atomic charge distribution of the title compound for B3LYP/6$311 \mathrm{G}$ basis set. Atomic charges of all carbon atoms are negative except C6, C12 and C13; those are bonded with nitro and carboxylic acid groups. Due to the reason of electronegative atoms attached with the carbon atoms pull out the partial charges from these atoms. Hence these carbon atoms become positive charges. The extremely maximum protonated and deprotonated atoms are C13 (0.655 e) and N5 (-0.795 e) respectively. All the hydrogen atoms acquire positive Mulliken atomic charge. The charge distribution shows that $\mathrm{O} 1, \mathrm{O} 2, \mathrm{O} 3$ and $\mathrm{O} 4$ are negatively charged. The biggest value of charge (0.402 e) is noticed for H20 may be due to hydrogen bonding.

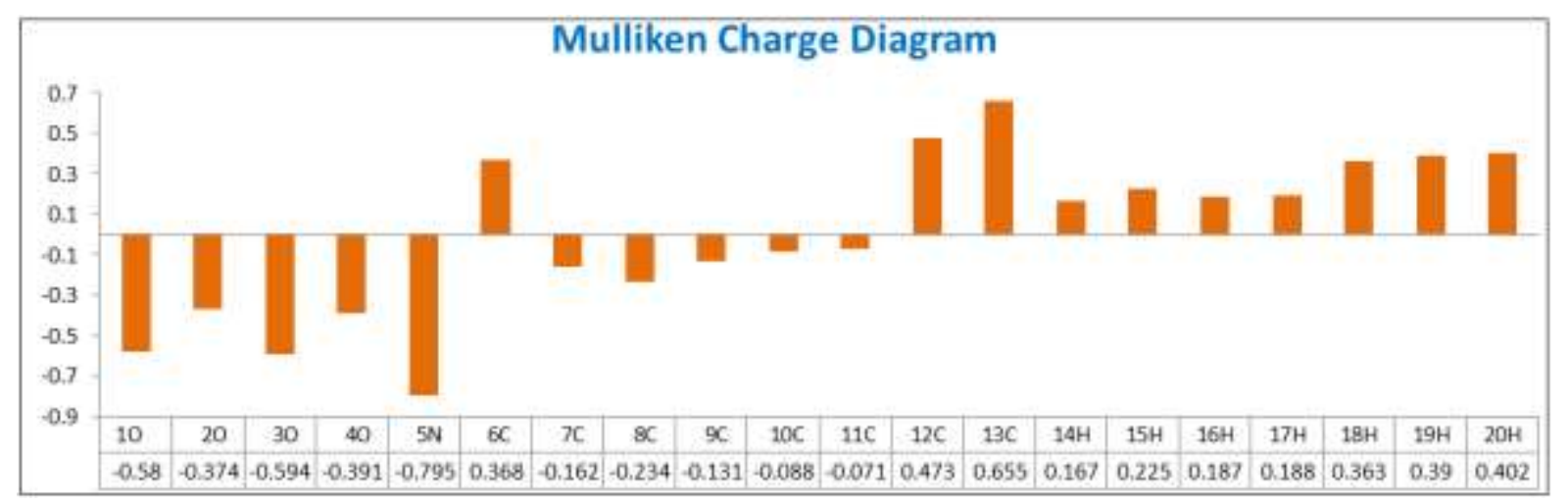

Fig. 11: The atomic charge distribution of the title compound for B3LYP/6-311G basis set

\subsection{Force constant and reduced masses}

The force constant and reduced mass of 4-(carboxyamino)-benzoic acid molecule calculated using DFT-B3LYP/6-311G and are shown in Figure 12 and 13. In Figure 12, Force constant can be divided into two regions; the first part range is from 0 to $1600 \mathrm{~cm}^{-1}$. The second part range is from $1600 \mathrm{~cm}^{-1}$ to near $3700 \mathrm{~cm}^{-1}$. The highest force constant value is 13.92 mDyne/A. In Figure 13, the title molecule has highest reduced mass at 9.33 a.u. According to the formula $v=\frac{1}{2 \pi} \sqrt{\frac{k}{\mu}}$, the reduced mass is inversely proportional to the frequency and force constant is directly proportional to the frequency. Figure 12 and 13 shows that the values of reduced mass are decreasing and force constant are increasing. 


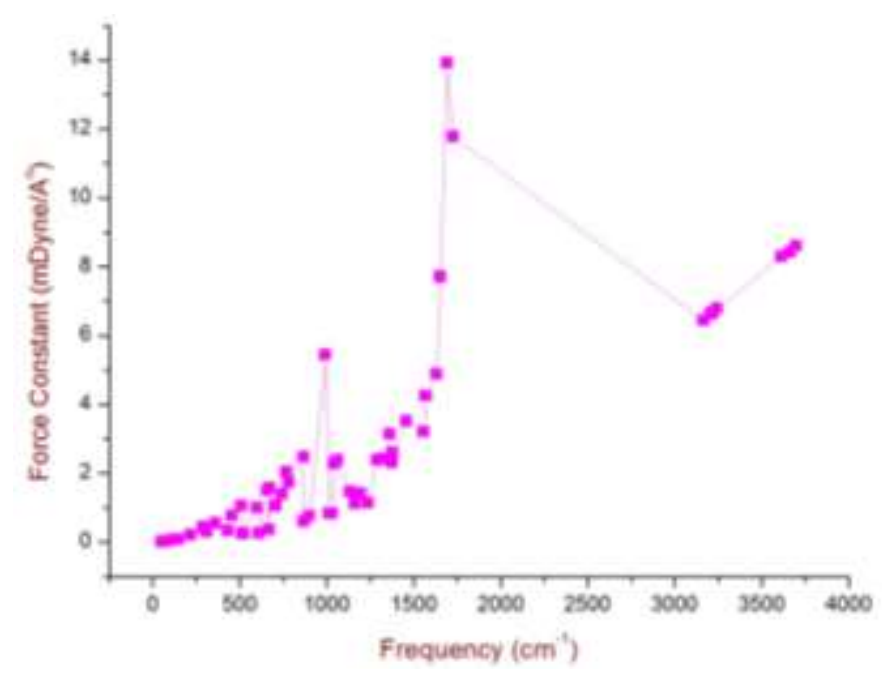

Fig. 12: The force constant for title molecule

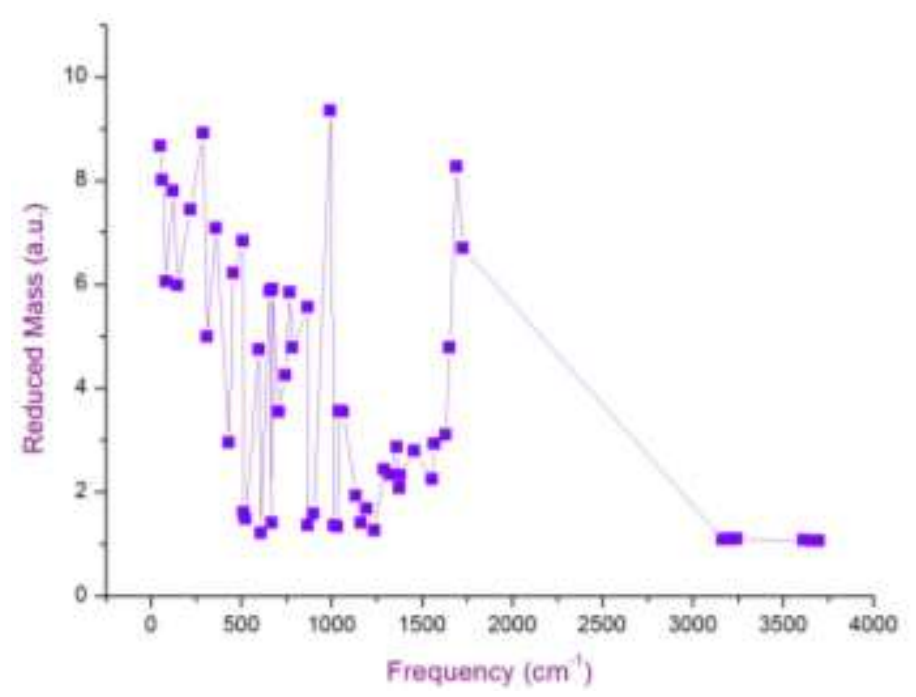

Fig. 13: The reduced mass for title molecule

\subsection{Donor-acceptor interactions}

NBO is an efficient method to understand the intra and inter-molecular non-bonded interactions for bio-molecular compounds. Table 5 shows the occupancy and energies of $i$ and $\mathrm{j}$ orbitals with the $\Delta E_{i j}$ of the most significant lone pair (LP) and bonding $(\sigma / \pi)$ to antibonding $\left(\sigma^{*} / \pi^{*}\right)$ transitions. Some significant orbital interactions and corresponding second order perturbation energies derived from the NBO computation for the compound 4(carboxyamino)-benzoic acid. The Donor-acceptor interactions are happened between filled Lewis and empty non-Lewis NBOs after estimating their energies through second order perturbation theory. These interactions are termed as 'delocalization' corrections to the zeroth-order natural Lewis structure. The energy of these delocalization interactions $\mathrm{E}(2)$ is 
proportional to the NBO interacting intensities and energies which gives the interactions among various parts of the molecules[53-55]. For each donor (i) and acceptor (j), the interaction energy $\mathrm{E}(2)$ was obtained from the standard second order perturbation approach $E_{2}=\Delta E_{i j}=q_{i} \frac{F(i, j)^{2}}{E_{i}-E_{j}}$. Where the term $\mathrm{q}_{\mathrm{i}}$ refers the occupancy of donor orbital, $\mathrm{E}_{\mathrm{i}}$ and $\mathrm{E}_{\mathrm{j}}$ denote the energies of donating and accepting orbitals and $F(i, j)^{2}$ is the KS matrix (Fock matrix) between $\mathrm{i}$ and $\mathrm{j}$ NBO orbitals. Table 8 shows the most significant interactions between Lewis and non-Lewis orbital with $\mathrm{O}$ and $\mathrm{N}$ lone pairs. The $\mathrm{N} 5$ lone pair to the adjacent anti-bonding orbital of the ring $\left[\mathrm{N} 5 \rightarrow \pi^{*}(\mathrm{O} 4-\mathrm{C} 13)\right]$ was the significantly important. The stabilization energy of this interaction is $71.78 \mathrm{kcal} / \mathrm{mol}$. The $\mathrm{O} 4-\mathrm{C} 13$ ties well and shows the biological activity because of the oxidation property. The stabilization energy $\mathrm{E}(2)$ associated with the interaction $\left[\mathrm{O} 1 \rightarrow \pi^{*}(\mathrm{O} 2-\mathrm{C} 12)\right]$ is obtained as $43.52 \mathrm{kcal} / \mathrm{mol}$. The high intra molecular hyper conjugative interaction of $\pi^{*}(\mathrm{O} 2-\mathrm{C} 12)$ distributes to $\pi^{*}(\mathrm{C} 7-\mathrm{C} 11)$ with energy of $51.36 \mathrm{kcal} / \mathrm{mol}$. Similarly, large energy is obtained by the transition $\pi(\mathrm{O} 2-\mathrm{C} 12)$ to $\pi^{*}(\mathrm{C} 7-\mathrm{C} 11)$; $\pi(\mathrm{C} 6-\mathrm{C} 9)$ to $\pi^{*}(\mathrm{C} 7-\mathrm{C} 11) ; \pi(\mathrm{C} 7-\mathrm{C} 11)$ to $\pi^{*}(\mathrm{C} 8-\mathrm{C} 10) ; \pi(\mathrm{C} 8-\mathrm{C} 10)$ to $\pi^{*}(\mathrm{C} 6-\mathrm{C} 9)$ with energies $28.53,24.33,23.27$ and $22.64 \mathrm{kcal} / \mathrm{mol}$ respectively.

Table 5: Stabilization energies obtained from the most significant lone pair to antibonding transition of the compound 4-(carboxyamino)-benzoic acid

\begin{tabular}{|c|c|c|c|c|c|c|c|c|}
\hline $\begin{array}{c}\text { Donor } \\
\text { NBO(i) }\end{array}$ & Type & ED/e & $\begin{array}{c}\text { Acceptor } \\
\text { NBO(j) }\end{array}$ & Type & ED/e & $\begin{array}{c}\mathbf{E}(\mathbf{2})^{\mathbf{a}} \\
\mathbf{K c a l} / \mathbf{m o l}\end{array}$ & $\begin{array}{c}\mathbf{E}(\mathbf{j})-\mathbf{E}(\mathbf{i})^{\mathbf{b}} \\
\mathbf{a . u .}\end{array}$ & $\begin{array}{c}\mathbf{F}(\mathbf{i}, \mathbf{j})^{\mathbf{c}} \\
\mathbf{a . u .}\end{array}$ \\
\hline O1 - C12 & $\sigma$ & 1.99514 & $\mathrm{C} 7-\mathrm{C} 10$ & $\sigma^{*}$ & 0.02329 & 1.89 & 1.46 & 0.047 \\
\hline O1 - H19 & $\sigma$ & 1.98916 & O2 - C12 & $\sigma^{*}$ & 0.01875 & 1.07 & 1.27 & 0.033 \\
\hline O1 - H19 & $\sigma$ & 1.98916 & C7 - C12 & $\sigma^{*}$ & 0.05974 & 3.29 & 1.18 & 0.056 \\
\hline O2 - C12 & $\sigma$ & 1.99522 & C7 - C11 & $\sigma^{*}$ & 0.02420 & 1.37 & 1.60 & 0.042 \\
\hline O2 - C12 & $\sigma$ & 1.99522 & C7 - C12 & $\sigma^{*}$ & 0.05974 & 2.50 & 1.48 & 0.055 \\
\hline O2 - C12 & $\pi$ & 1.98238 & O2 - C12 & $\pi^{*}$ & 0.27326 & 1.07 & 0.36 & 0.019 \\
\hline O2 - C12 & $\pi$ & 1.98238 & C7 - C11 & $\pi^{*}$ & 0.38314 & 4.81 & 0.40 & 0.043 \\
\hline O3 - C13 & $\sigma$ & 1.99251 & N5 - C6 & $\sigma^{*}$ & 0.02891 & 3.08 & 1.30 & 0.057 \\
\hline O3 - H20 & $\sigma$ & 1.98888 & O4 - C13 & $\sigma^{*}$ & 0.02014 & 0.77 & 1.28 & 0.028 \\
\hline O3 - H20 & $\sigma$ & 1.98888 & N5 - C13 & $\sigma^{*}$ & 0.06783 & 3.24 & 1.17 & 0.056 \\
\hline O4 - C13 & $\sigma$ & 1.99540 & N5 - C13 & $\sigma^{*}$ & 0.06783 & 2.08 & 1.47 & 0.050 \\
\hline O4 - C13 & $\sigma$ & 1.99540 & N5 - H18 & $\sigma^{*}$ & 0.01388 & 1.04 & 1.44 & 0.035 \\
\hline O4 - C13 & $\pi$ & 1.99491 & O4 - C13 & $\pi^{*}$ & 0.36480 & 2.83 & 0.35 & 0.031 \\
\hline N5 - C6 & $\sigma$ & 1.98488 & O3 - C13 & $\sigma^{*}$ & 0.10377 & 1.71 & 1.08 & 0.039 \\
\hline N5 - C6 & $\sigma$ & 1.98488 & N5 - C13 & $\sigma^{*}$ & 0.06783 & 1.32 & 1.22 & 0.036 \\
\hline N5 - C6 & $\sigma$ & 1.98488 & N5 - H18 & $\sigma^{*}$ & 0.01388 & 0.58 & 1.20 & 0.024 \\
\hline N5 - C6 & $\sigma$ & 1.98488 & C6 - C8 & $\sigma^{*}$ & 0.02281 & 1.26 & 1.35 & 0.037 \\
\hline N5 - C6 & $\sigma$ & 1.98488 & C6 - C9 & $\sigma^{*}$ & 0.02467 & 1.63 & 1.36 & 0.042 \\
\hline N5 - C6 & $\sigma$ & 1.98488 & C8 - C10 & $\sigma^{*}$ & 0.01326 & 1.52 & 1.39 & 0.041 \\
\hline N5 - C6 & $\sigma$ & 1.98488 & C9 - C11 & $\sigma^{*}$ & 0.01487 & 1.33 & 1.39 & 0.038 \\
\hline N5 - C13 & $\sigma$ & 1.98908 & O3 - H20 & $\sigma^{*}$ & 0.00632 & 1.30 & 1.21 & 0.036 \\
\hline N5 - C13 & $\sigma$ & 1.98908 & O4 - C13 & $\sigma^{*}$ & 0.02014 & 1.44 & 1.38 & 0.040 \\
\hline N5 - C13 & $\sigma$ & 1.98908 & N5 - C6 & $\sigma^{*}$ & 0.02891 & 1.51 & 1.25 & 0.039 \\
\hline
\end{tabular}




\begin{tabular}{|c|c|c|c|c|c|c|c|c|}
\hline N5 - C13 & $\sigma$ & 1.98908 & C6 - C8 & $\sigma^{*}$ & 0.02281 & 1.82 & 1.39 & 0.045 \\
\hline N5 - H18 & $\sigma$ & 1.98313 & $\mathrm{O} 3-\mathrm{C} 13$ & $\sigma^{*}$ & 0.10377 & 1.37 & 0.94 & 0.033 \\
\hline N5 - H18 & $\sigma$ & 1.98313 & $\mathrm{O} 4-\mathrm{C} 13$ & $\sigma^{*}$ & 0.02014 & 4.72 & 1.19 & 0.067 \\
\hline N5 - H18 & $\sigma$ & 1.98313 & C6 - C9 & $\sigma^{*}$ & 0.02467 & 3.90 & 1.21 & 0.062 \\
\hline C6 - C8 & $\sigma$ & 1.97208 & N5 - C6 & $\sigma^{*}$ & 0.02891 & 1.28 & 1.10 & 0.034 \\
\hline C6 - C8 & $\sigma$ & 1.97208 & N5 - C13 & $\sigma^{*}$ & 0.06783 & 3.54 & 1.11 & 0.057 \\
\hline C6 - C8 & $\sigma$ & 1.97208 & C6 - C9 & $\sigma^{*}$ & 0.02467 & 4.16 & 1.25 & 0.064 \\
\hline C6 - C8 & $\sigma$ & 1.97208 & $\mathrm{C} 8-\mathrm{C} 10$ & $\sigma^{*}$ & 0.01326 & 3.04 & 1.28 & 0.056 \\
\hline C6 - C9 & $\sigma$ & 1.97343 & C6 - C8 & $\sigma^{*}$ & 0.02281 & 4.37 & 1.23 & 0.066 \\
\hline C6 - C9 & $\pi$ & 1.62122 & C7 - C11 & $\pi^{*}$ & 0.38314 & 24.33 & 0.29 & 0.075 \\
\hline C6 - C9 & $\pi$ & 1.62122 & $\mathrm{C} 8-\mathrm{C} 10$ & $\pi^{*}$ & 0.29521 & 16.43 & 0.28 & 0.062 \\
\hline C7 - C10 & $\sigma$ & 1.97153 & C7 - C11 & $\sigma^{*}$ & 0.02420 & 4.47 & 1.24 & 0.067 \\
\hline C7 - C10 & $\sigma$ & 1.97153 & C8 - C10 & $\sigma^{*}$ & 0.01326 & 2.82 & 1.26 & 0.053 \\
\hline $\mathrm{C} 7-\mathrm{C} 10$ & $\sigma$ & 1.97153 & C8 - H14 & $\sigma^{*}$ & 0.01432 & 2.57 & 1.11 & 0.048 \\
\hline $\mathrm{C} 7-\mathrm{C} 11$ & $\sigma$ & 1.97488 & $\mathrm{C} 7-\mathrm{C} 10$ & $\sigma^{*}$ & 0.02329 & 4.59 & 1.24 & 0.067 \\
\hline $\mathrm{C} 7-\mathrm{C} 11$ & $\sigma$ & 1.97488 & C9-C11 & $\sigma^{*}$ & 0.01487 & 2.65 & 1.27 & 0.052 \\
\hline $\mathrm{C} 7-\mathrm{C} 11$ & $\pi$ & 1.63175 & $\mathrm{O} 2-\mathrm{C} 12$ & $\pi^{*}$ & 0.27326 & 28.53 & 0.23 & 0.075 \\
\hline $\mathrm{C} 7-\mathrm{C} 11$ & $\Pi$ & 1.63175 & C6 - C9 & $\pi^{*}$ & 0.38058 & 18.23 & 0.27 & 0.063 \\
\hline $\mathrm{C} 7-\mathrm{C} 11$ & $\pi$ & 1.63175 & $\mathrm{C} 8-\mathrm{C} 10$ & $\pi^{*}$ & 0.29521 & 23.27 & 0.27 & 0.073 \\
\hline $\mathrm{C} 7-\mathrm{C} 12$ & $\sigma$ & 1.97588 & C7 - C11 & $\sigma^{*}$ & 0.02420 & 2.73 & 1.23 & 0.052 \\
\hline $\mathrm{C} 7-\mathrm{C} 12$ & $\sigma$ & 1.97588 & $\mathrm{C} 8-\mathrm{C} 10$ & $\sigma^{*}$ & 0.01326 & 2.51 & 1.25 & 0.050 \\
\hline $\mathrm{C} 8-\mathrm{C} 10$ & $\pi$ & 1.69335 & C6 - C9 & $\pi^{*}$ & 0.38058 & 22.64 & 0.28 & 0.072 \\
\hline $\mathrm{C} 8-\mathrm{C} 10$ & $\pi$ & 1.69335 & C7 - C11 & $\pi^{*}$ & 0.38314 & 16.26 & 0.29 & 0.062 \\
\hline C8 - H14 & $\sigma$ & 1.97824 & C6 - C9 & $\sigma^{*}$ & 0.02467 & 4.37 & 1.06 & 0.061 \\
\hline C8 - H14 & $\sigma$ & 1.97824 & $\mathrm{C} 7-\mathrm{C} 10$ & $\sigma^{*}$ & 0.02329 & 4.01 & 1.07 & 0.059 \\
\hline C9 - C11 & $\sigma$ & 1.97508 & N5 - C6 & $\sigma^{*}$ & 0.02891 & 4.66 & 1.09 & 0.064 \\
\hline C9 - C11 & $\sigma$ & 1.97508 & C7 - C12 & $\sigma^{*}$ & 0.05974 & 3.65 & 1.13 & 0.058 \\
\hline C9 - H15 & $\sigma$ & 1.97608 & C6 - C8 & $\sigma^{*}$ & 0.02281 & 4.57 & 1.04 & 0.061 \\
\hline C9 - H15 & $\sigma$ & 1.97608 & C7 - C11 & $\sigma^{*}$ & 0.02420 & 4.24 & 1.06 & 0.060 \\
\hline C10 - H16 & $\sigma$ & 1.97740 & C6 - C8 & $\sigma^{*}$ & 0.02281 & 4.40 & 1.04 & 0.060 \\
\hline C11 - H17 & $\sigma$ & 1.97730 & C6 - C9 & $\sigma^{*}$ & 0.02467 & 4.57 & 1.05 & 0.062 \\
\hline C11 - H17 & $\sigma$ & 1.97730 & $\mathrm{C} 7-\mathrm{C} 10$ & $\sigma^{*}$ & 0.02329 & 4.83 & 1.06 & 0.064 \\
\hline $\mathrm{O} 1$ & LP(1) & 1.97975 & $\mathrm{O} 2-\mathrm{C} 12$ & $\sigma^{*}$ & 0.01875 & 5.83 & 1.12 & 0.072 \\
\hline O1 & $\mathrm{LP}(2)$ & 1.83397 & $\mathrm{O} 2-\mathrm{C} 12$ & $\pi^{*}$ & 0.27326 & 43.52 & 0.31 & 0.106 \\
\hline $\mathrm{O} 2$ & $\mathrm{LP}(2)$ & 1.85772 & $\mathrm{O} 1-\mathrm{C} 12$ & $\sigma^{*}$ & 0.10158 & 33.96 & 0.54 & 0.123 \\
\hline $\mathrm{O} 2$ & $\mathrm{LP}(2)$ & 1.85772 & C7 - C12 & $\sigma^{*}$ & 0.05974 & 15.25 & 0.69 & 0.094 \\
\hline $\mathrm{O} 3$ & $\mathrm{LP}(1)$ & 1.97894 & $\mathrm{O} 4-\mathrm{C} 13$ & $\sigma^{*}$ & 0.02014 & 6.39 & 1.13 & 0.076 \\
\hline $\mathrm{O} 3$ & $\mathrm{LP}(2)$ & 1.86072 & $\mathrm{O} 4-\mathrm{C} 13$ & $\pi^{*}$ & 0.36480 & 40.92 & 0.30 & 0.105 \\
\hline $\mathrm{O} 4$ & $\mathrm{LP}(2)$ & 1.84065 & $\mathrm{O} 3-\mathrm{C} 13$ & $\sigma^{*}$ & 0.10377 & 33.42 & 0.53 & 0.121 \\
\hline O4 & $\mathrm{LP}(2)$ & 1.84065 & N5 - C13 & $\sigma^{*}$ & 0.06783 & 21.45 & 0.67 & 0.110 \\
\hline N5 & $\mathrm{LP}(1)$ & 1.67344 & $\mathrm{O} 4-\mathrm{C} 13$ & $\pi^{*}$ & 0.36480 & 71.78 & 0.24 & 0.119 \\
\hline N5 & LP(1) & 1.67344 & C6 - C9 & $\pi^{*}$ & 0.38058 & 34.85 & 0.30 & 0.092 \\
\hline $\mathrm{O} 2-\mathrm{C} 12$ & $\pi^{*}$ & 0.27326 & $\mathrm{C} 7-\mathrm{C} 11$ & $\pi^{*}$ & 0.38314 & 51.36 & 0.04 & 0.074 \\
\hline $\mathrm{O} 3-\mathrm{C} 13$ & $\sigma^{*}$ & 0.10377 & N5 - C6 & $\sigma^{*}$ & 0.02891 & 1.77 & 0.13 & 0.052 \\
\hline
\end{tabular}

\subsection{Reduced gradient of density (RDG)}

By employing NCI analysis, it is possible to determine the nature of the interactions based on electron density and the sign of the second derivative in the perpendicular direction of the bond ( $\lambda 2)$. RDG density is a dimensionless quantity and is written in the following form [56]: 


$$
R D G(r)=\frac{1}{2\left(3 \pi^{2}\right)^{1 / 3}} \frac{|\nabla \rho(r)|}{\rho(r)^{4 / 3}}
$$

We have represented, in Figure 13, a 2D plot of RDG, as a characteristic of the electron density accelerated by means of the signal of the second eigenvalue of the matrix of Hessian. $\lambda 2$ is the greatest eigenvalue of the Hessian matrix which characterizes the fluctuation of the density in the vicinity of the critical point. From the value of the sign $(\lambda 2)^{*} \rho$, we can distinguish between the one kinds of non-covalent interactions. The $-\lambda 2$ confirms a bonding interaction, such as hydrogen bonds, whereas $+\lambda 2$ shows nonbonding interactions and Vander Waals interactions can be determined by negligible values of $\lambda 2$. According to figure 14 , the red, green and blue circles indicate repulsive interactions (steric effect), VDW and H-bond respectively. Generally, VDW interactions have very low electron densities. The regions of interactions corresponding to the hydrogen bond and the repulsive interactions have a high density. The blue circle confirms H-bond formation between the title molecules.

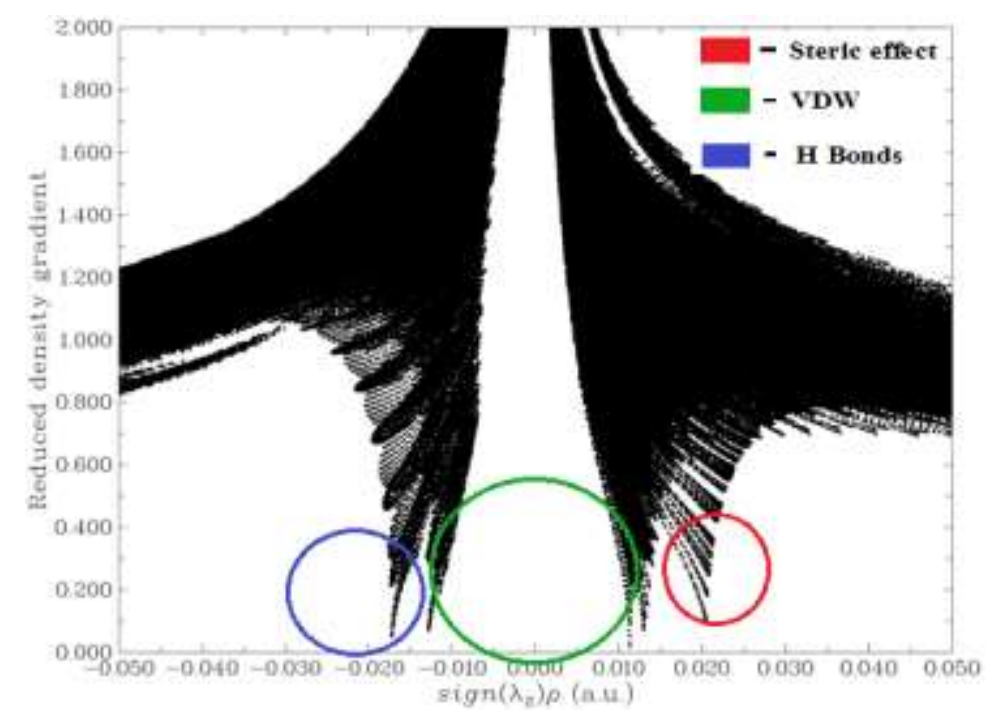

Fig. 14: Graphical representation of the reduced density gradient versus the electron density

\subsection{Thermodynamic Properties}

Thermodynamic data obtained from theoretical methods are very important for understanding the chemical processes. DFT is efficient tool to predict various statistical thermodynamic properties of chemical compounds. On the basis of vibrational analysis at DFT-B3LYP and HF methods with basis set 6-311G and 6-31G level, the standard thermodynamic functions heat capacity, entropy, enthalpy, zero point vibrational energy, thermal energy and dipole moment for the title compound were found from the theoretical harmonic frequencies and presented in Table 6. These parameters obtained here give available information for the 
further studies on the title compound and also estimate directions of chemical reactions according to the second law of thermodynamics. The ZPVE is lower in DFT/6-311G than HF/6-31G. Variations of the ZPVE seems to be important [57-59]. The biggest value of ZPVE of the title compound is $100.78414 \mathrm{Kcal} \mathrm{mol}^{-1}$. As a result of HF method calculation the highest dipole moment was 2.6123 Debye. The highest values of specific heat capacity and entropy were gotten for B3LYP/6-311G method.

Table 6: Calculated thermodynamic parameters using HF/6-31G and DFT-B3LYP/6-311G methods

\begin{tabular}{|c|c|c|}
\hline $\begin{array}{c}\text { Thermodynamic Parameters } \\
\text { (298.15 K) }\end{array}$ & DFT/6-311G & HF/6-31G \\
\hline SCF energy & -664.73434 & -660.6995 \\
\hline $\begin{array}{l}\text { Total energy (Thermal), } \\
\mathrm{E}_{\text {total }}\left(\mathrm{Kcal} \mathrm{mol}^{-1}\right)\end{array}$ & 99.348 & 107.211 \\
\hline $\begin{array}{l}\text { Translational energy, } \\
\mathrm{E}_{\text {tran }}\left(\mathrm{Kcal} \mathrm{mol}^{-1}\right)\end{array}$ & 0.889 & 0.889 \\
\hline 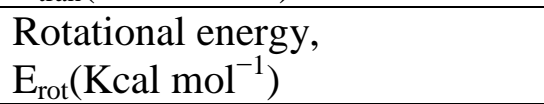 & 0.889 & 0.889 \\
\hline $\begin{array}{l}\text { Vibrational energy, } \\
\mathrm{E}_{\mathrm{vib}}\left(\mathrm{Kcal} \mathrm{mol}^{-1}\right)\end{array}$ & 97.570 & 105.433 \\
\hline $\begin{array}{l}\text { Zero point vibrational } \\
\text { energy, } \mathrm{E}_{0}\left(\mathrm{Kcal} \mathrm{mol}^{-1}\right)\end{array}$ & 92.42369 & 100.78414 \\
\hline $\begin{array}{l}\text { Heat capacity, } \\
\mathrm{C}_{\mathrm{v}}(\mathrm{Cal} / \text { Mol-Kelvin })\end{array}$ & 41.678 & 38.141 \\
\hline $\begin{array}{l}\text { Entropy, S } \\
\text { (Cal/Mol-Kelvin) }\end{array}$ & 105.214 & 102.121 \\
\hline \multicolumn{3}{|l|}{$\begin{array}{l}\text { Rotational constants } \\
\text { (GHZ) }\end{array}$} \\
\hline $\mathrm{A}$ & 2.72089 & 2.79879 \\
\hline $\mathrm{B}$ & 0.33939 & 0.34400 \\
\hline $\mathrm{C}$ & 0.30175 & 0.30635 \\
\hline Dipole moment (Debye) & 2.5869 & 2.6123 \\
\hline
\end{tabular}

\subsection{ADMET and drug like nature assessment}

The significant rule or filter of drug-likeness is "Rule of Five" recommended by Lipinski, which describes the five principles of orally active compounds for physicochemical properties [60]. According to Lipinski's standard of five, that the molecule is discovered to be orally bioactive with the following factors, Molecular weight $<500$, Mi $\log \mathrm{P}<5, \mathrm{HBD}$ is not exactly or equivalent to 5, HBA is not exactly or equivalent to 10 and Polar surface area is less than $120 \AA^{2}$ [61]. These molecular properties were determined by using Molinspiration software. This web tool is freely accessible (https://www.molinspiration.com). The assessed druglikeness properties of the title molecule are recorded in Table 7 . The bioavailability score is 
obtained to be 0.56 . This shows that the title molecule is a better candidate for biological properties and hence applied for docking studies. Medication applicants ought to have ideal ADMET prediction. The ADMET for title molecule is obtained utilizing the pkCSM-ADME program which is freely accessible through web tool (http://biosig.unimelb.edu.au/pkcsm/). This is an important tool to enable medicinal scientists to discover the balance between pharmacokinetic, potency, and toxicity evaluation. The title compound was assessed by their Absorption, Distribution, Metabolism, Excretion and Toxicity were analyzed and classified in Table 8. The $\mathrm{CaCo} 2$ permeability and low permeability for skin is resolved to assess the absorption of title compound were obtained to be $0.0643 \mathrm{~ns} \mathrm{~m}^{-1}$ and $-2.735 \mathrm{log} \mathrm{kp}$. The Human Intestinal Absorption is the most important factor for a drug molecule which usually lies between 70 to $100 \%$. It determines good intestinal absorption for drug molecules. The HIA value of title molecule was found to be $97.63 \%$, which is well absorbed for the human body [62,63]. The limitation of a drug to enter the brain is a critical limit that ought to be considered to decrease side effects and toxicity and the measured value for the title molecule is -0.824 [64]. The value of skin permability is -2.735 which specifies that the compound cannot be absorbed by human skin. The pure water solubility was found to be low value (-2.513). This 4-(carboxyamino)benzoic acid clearly less harmful accordingly. The 4-(carboxyamino)benzoic acid is a non-inhibitor of P-glycoprotein and it doesn't interfere with the P-glycoprotein's in drug absosrption and excretion. Here GI absorption (gastro intestinal) is high. It is a non-inhibitor of CYP1A2, CYP2C19, CYP2C9, CYP2D6, CYP3A4 enzymes. These things specify that this molecule can be safeguarded as an imminent aspirant for bioactive cases. Excretion also predicts to be non-substrate of Organic Cation Transporter2 (OCT2). The toxicity of the AMES exhibiting negative shows that its non-cancer and nonmutagenic molecule. It does not inhibit hERG-I and hERG-II and also does not cause skin sensitivity. T.pyriformis Toxicity and minnow toxicity of the title compound was determined to be $0.282 \log \mathrm{ug} / \mathrm{L}$ and $2.525 \log \mathrm{mM}$ [65-67]. Every one of the parameters result mentions that the title molecule has been the biological activity of the drug in future.

Table 7: Molinspiration property values of 4-(carboxyamino) benzoic acid

\begin{tabular}{|l|c|c|}
\hline \multicolumn{1}{|c|}{ Descriptors } & Values & Expected range \\
\hline Hydrogen bond donor $(\mathrm{HBD})$ & 3 & $<5$ \\
\hline Hydrogen bond acceptor $(\mathrm{HBA})$ & 4 & $<10$ \\
\hline Partition coefficient $(\mathrm{Mi} \log )$ & 0.94 & $<5$ \\
\hline Molecular weight $($ dalton$)$ & 181.15 & $<500$ \\
\hline Polar surface area $(\mathrm{PSA})\left(\AA^{2}\right)$ & 86.62 & $<120$ \\
\hline Number of rotatable bonds & 2 & $40-130$ \\
\hline Molar refractivity & 44.87 & \\
\hline
\end{tabular}




\begin{tabular}{|l|c|c|}
\hline Bioavailability score & 0.56 & 0.55 \\
\hline
\end{tabular}

Table 8: Pharmacokinetic descriptors of pkCSM-ADMET properties for 4-(carboxyamino)benzoic acid

\begin{tabular}{|c|c|c|c|}
\hline Property & Model Name & $\begin{array}{l}\text { Predicted } \\
\text { Value }\end{array}$ & Unit \\
\hline Absorption & Water solubility & -2.513 & Numeric (log mol/L) \\
\hline Absorption & Caco2 permeability & 0.643 & Numeric $\left(\log\right.$ Papp in $\left.10^{-6} \mathrm{~cm} / \mathrm{s}\right)$ \\
\hline Absorption & Human Intestinal absorption & 97.63 & Numeric (\% Absorbed) \\
\hline Absorption & Skin Permeability & -2.735 & Numeric $(\log K p)$ \\
\hline Absorption & P-glycoprotein substrate & No & Categorical (Yes/No) \\
\hline Absorption & P-glycoprotein I inhibitor & No & Categorical (Yes/No) \\
\hline Absorption & P-glycoprotein II inhibitor & No & Categorical (Yes/No) \\
\hline Distribution & VDss (human) & -2.129 & Numeric $(\log \mathrm{L} / \mathrm{kg})$ \\
\hline Distribution & Fraction unbound (human) & 0.574 & Numeric $(\mathrm{Fu})$ \\
\hline Distribution & BBB permeability & -0.824 & Numeric $(\log B B)$ \\
\hline Distribution & CNS permeability & -3.349 & Numeric $(\log$ PS) \\
\hline Metabolism & CYP2D6 substrate & No & Categorical (Yes/No) \\
\hline Metabolism & CYP3A4 substrate & No & Categorical (Yes/No) \\
\hline Metabolism & CYP1A2 inhibitor & No & Categorical (Yes/No) \\
\hline Metabolism & CYP2C19 inhibitor & No & Categorical (Yes/No) \\
\hline Metabolism & CYP2C9 inhibitor & No & Categorical (Yes/No) \\
\hline Metabolism & CYP2D6 inhibitor & No & Categorical (Yes/No) \\
\hline Metabolism & CYP3A4 inhibitor & No & Categorical (Yes/No) \\
\hline Excretion & Total Clearance & 0.407 & Numeric $(\log \mathrm{ml} / \mathrm{min} / \mathrm{kg})$ \\
\hline Excretion & Renal OCT2 substrate & No & Categorical (Yes/No) \\
\hline Toxicity & AMES toxicity & No & Categorical (Yes/No) \\
\hline Toxicity & $\begin{array}{l}\text { Max. tolerated dose } \\
\text { (human) }\end{array}$ & 0.689 & Numeric (log mg/kg/day) \\
\hline Toxicity & hERG I inhibitor & No & Categorical (Yes/No) \\
\hline Toxicity & hERG II inhibitor & No & Categorical (Yes/No) \\
\hline Toxicity & $\begin{array}{l}\text { Oral Rat Acute Toxicity } \\
\text { (LD50) }\end{array}$ & 1.649 & Numeric (mol/kg) \\
\hline Toxicity & $\begin{array}{l}\text { Oral Rat Chronic Toxicity } \\
\text { (LOAEL) }\end{array}$ & 1.697 & Numeric (log mg/kg bw/day) \\
\hline Toxicity & Hepatotoxicity & No & Categorical (Yes/No) \\
\hline Toxicity & Skin Sensitisation & No & Categorical (Yes/No) \\
\hline Toxicity & Pyriformis toxicity & 0.282 & Numeric (log ug/L) \\
\hline Toxicity & Minnow toxicity & 2.525 & Numeric $(\log \mathrm{mM})$ \\
\hline
\end{tabular}

\subsection{Molecular Docking}

The Protein Data Bank (PDB) is the single, global archive for information about the 3D structure of biomacromolecules and their complexes, as determined by X-ray crystallography, NMR spectroscopy and cryoelectron microscopy. And also it includes more than a few Nobel Prize winning structures. Molecular docking is carried out for 4-(carboxyamino)-benzoic acid 
against active sites of four proteins. Regarding this issue the protein structures (PDB ID: 3UOW, 4WIN, 4WIO, 5DT6) were obtained from http://www.rcsb.org. Docking studies were performed by iGEMDOCK 2.1 program. The numbers of runs taken are 70 with population size 800 and 10 numbers of solutions. iGEMDOCK provides target protein and compound interaction profiles of electrostatic (E), hydrogen bonding $(\mathrm{H})$, and Vander Waal's (V) interactions. The empirical scoring function of iGEMDOCK was calculated by Fitness = VDW + Hbond + Elec. Whereas, VDW is vander Waal energy, Hbond and Elec are hydrogen bonding energy and electro static energy respectively [68]. Table 9 described the docking result of 4-(carboxyamino)-benzoic acid with four target proteins using iGEMDOCK. The docked poses of the compound with four target proteins were represented in Figure 15, 16, 17 and 18. For molecular docking, the protein 3UOW, 4WIN and 4WIO are GMP Synthetase binding protein from Plasmodium Falciparum which is essential to causative agent of the fatal form of malaria. GMPS is a vital protein in the purine biosynthetic pathway. Protein 5DT6 is glutamine receptor. The binding energy between compound and proteins 5DT6, 4WIO receptors are found to be -99.0424 and -95.151 respectively. In the interaction state of title molecule with 4 WIN receptor, the binding energy of corresponding receptor is found to be 87.7694. The highest binding energy of 4-(carboxyamino)-benzoic acid is observed against 3UOW with a binding energy of -69.6664 . The best molecule has the lowest binding energy. From the analysis of docking score and energy, the protein 5DT6 showed the best results than other proteins.

Table 9: Docking result of 4-(carboxyamino)-benzoic acid using iGEMDOCK.

\begin{tabular}{|c|c|c|c|c|c|c|}
\hline S.No. & $\begin{array}{c}\text { PDB } \\
\text { ID }\end{array}$ & Energy & VDW & H-Bond & Elec & Interacting residues \\
\hline 1 & 3UOW & -69.6664 & -46.1628 & -22.7832 & -0.720351 & $\begin{array}{l}\text { PHE-433, PRO-434, } \\
\text { GLN-476, LYS-547, } \\
\text { ILE-552, GLU-553, } \\
\text { GLN-476, ILE-552, } \\
\text { ILE-552, GLU-553, } \\
\text { GLU-553 }\end{array}$ \\
\hline 2 & $4 \mathrm{WIN}$ & -87.7694 & -60.5374 & -28.5852 & 1.35322 & 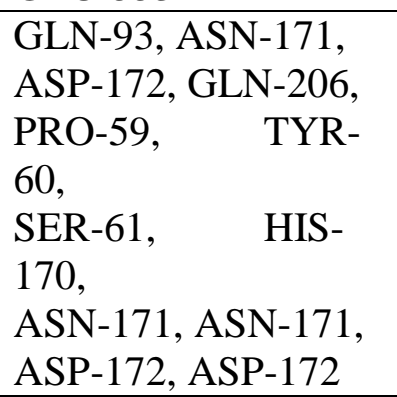 \\
\hline 3 & $4 \mathrm{WIO}$ & -95.151 & -62.8058 & -30.2687 & -2.07647 & SER-16, $\quad$ GLN- \\
\hline
\end{tabular}




\begin{tabular}{|c|c|c|c|c|c|c|}
\hline & & & & & & $\begin{array}{l}93, \\
\text { ASN-169, HIS-170, } \\
\text { ASN-171, ASP-172, } \\
\text { HIS-208, GLY-58, } \\
\text { ASN-169, HIS-170, } \\
\text { HIS-208 }\end{array}$ \\
\hline 4 & 5DT6 & -99.0424 & -60.1934 & -36.6199 & -2.2291 & $\begin{array}{l}\text { ARG-102, THR-97, } \\
\text { ARG-102, THR-143, } \\
\text { SER-148, THR-149, } \\
\text { THR-149, TRP-150, } \\
\text { TYR-66, } \\
\text { 148, } \\
\text { TYR-179, GLU-198 }\end{array}$ \\
\hline
\end{tabular}

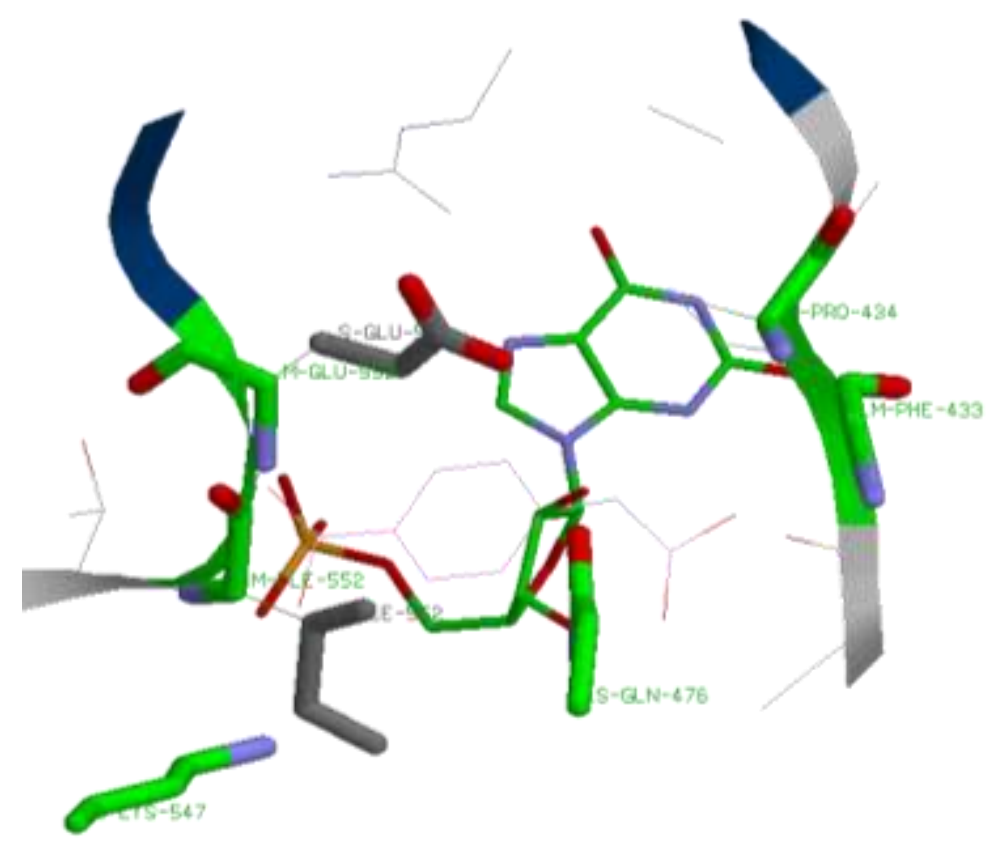

Fig. 15: The docked pose of the compound with $3 \mathrm{UOW}$ receptor 


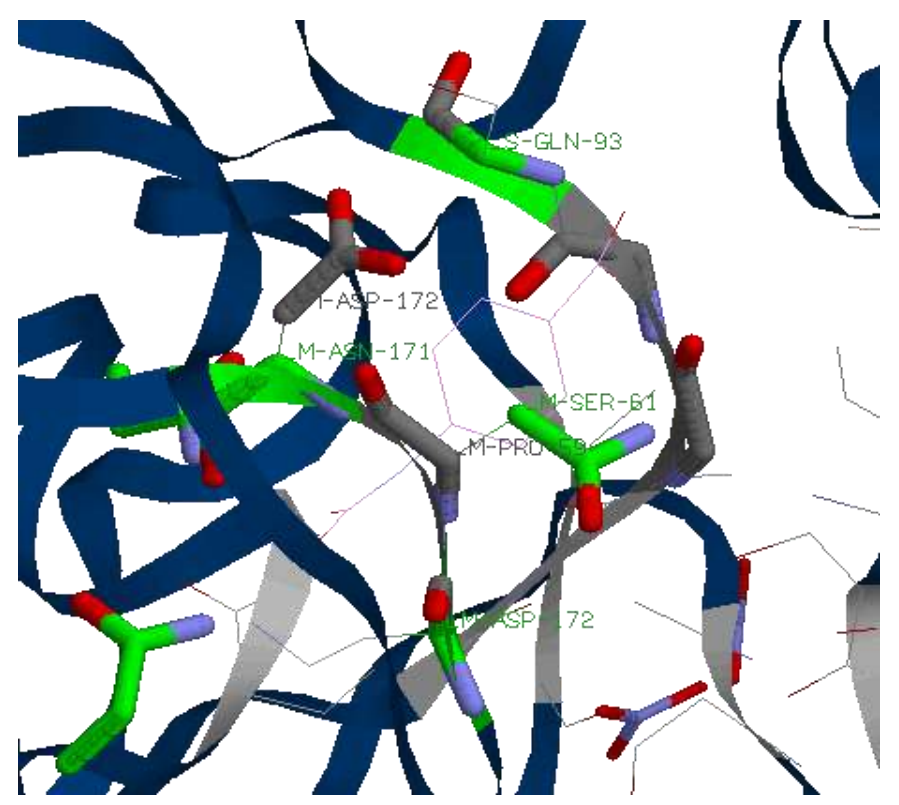

Fig. 16: The docked pose of the compound with $4 \mathrm{WIN}$ receptor

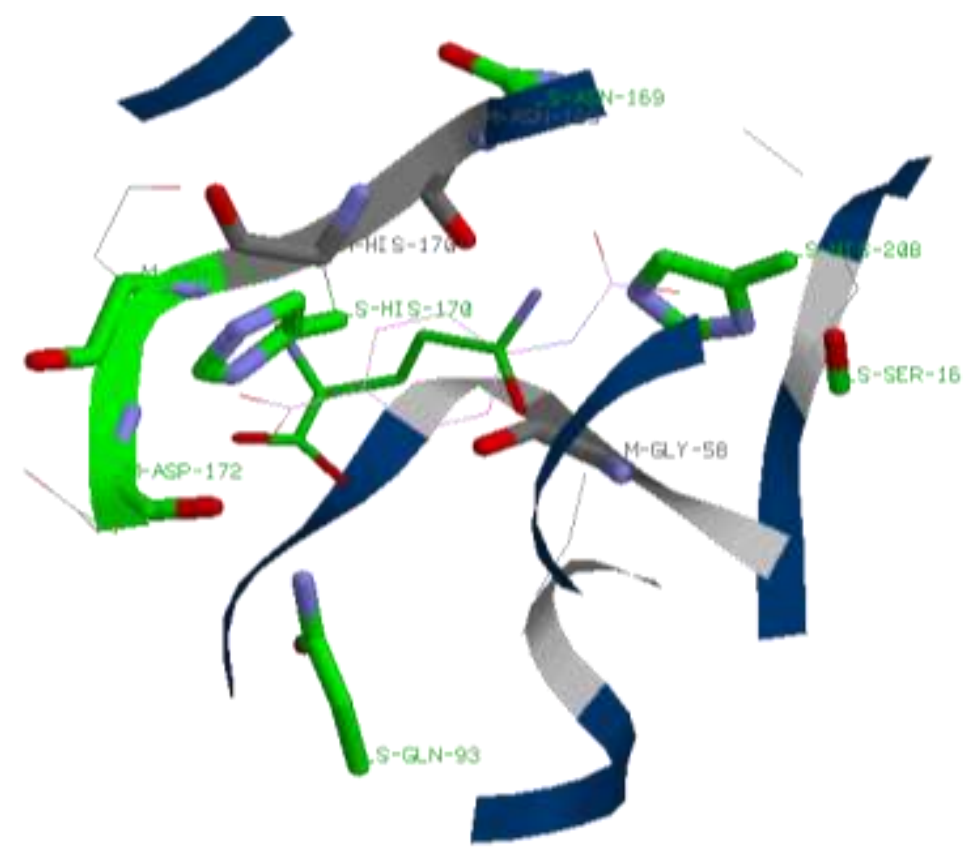

Fig. 17: The docked pose of the compound with 4 WIO receptor 


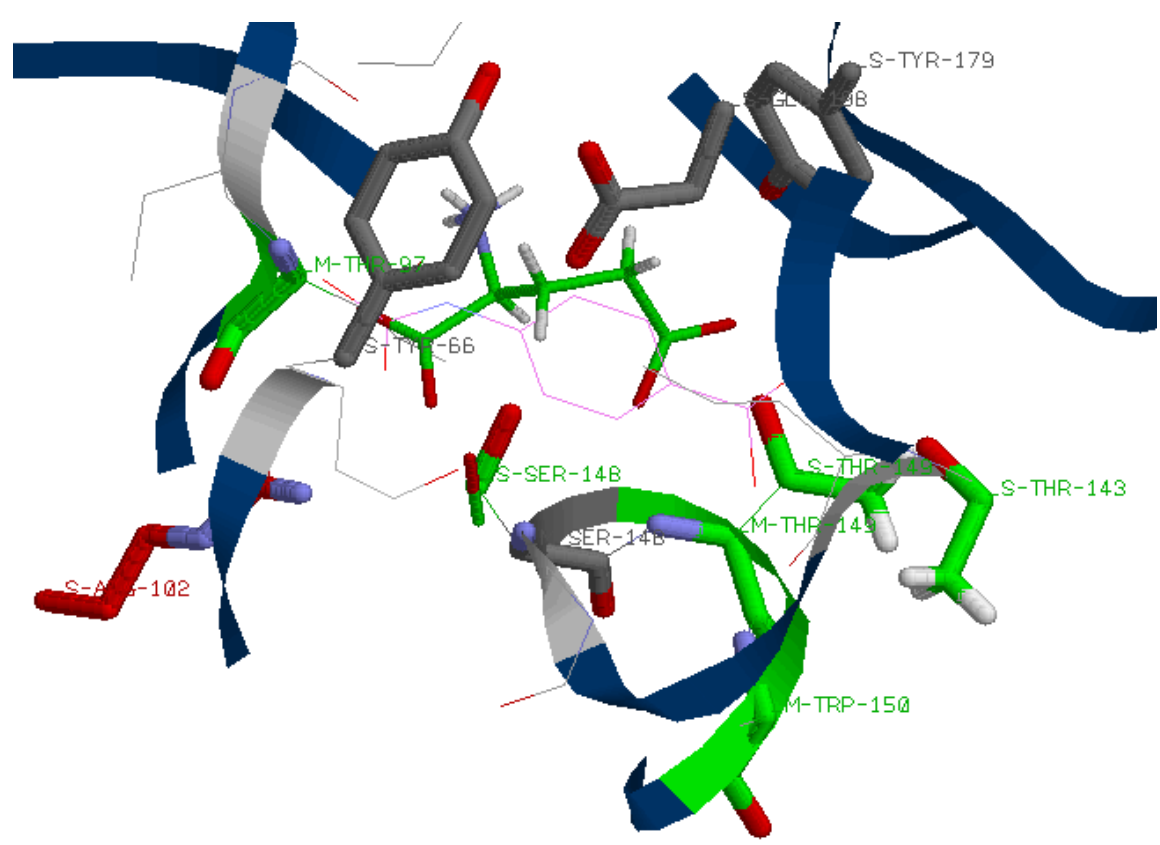

Fig. 18: The docked pose of the compound with 5DT6 receptor

\section{CONCLUSION}

In the present work, we have analyzed the ground state geometric structure of 4(carboxyamino)-benzoic acid together with spectroscopic signatures, electronic properties, biological activities and chemical reactivity predictions using quantum chemical computations. The theoretical spectral properties of title compound are successfully studied by IR, Raman, UV and NMR spectroscopic techniques. The various modes of vibrations are assigned on the results of PED value obtained from the normal coordinate analysis. TD-DFT calculations predict a peak at $281 \mathrm{~nm}$ which was due to the presence of two $\pi$ conjugated system of bonds $(\mathrm{C}=\mathrm{N}, \mathrm{C}=\mathrm{O})$ in the compound. The calculated HOMO-LUMO band gap energy value is $5.0 \mathrm{eV}$. It decides the significant degree of charge transfer interactions taking place in the compound and also it is responsible for the enhanced chemical as well as biological activity of the molecule. Under reactivity predictions molecular electrostatic potential map clearly demonstrates that the possible sites for electrophilic attack are mainly localised over oxygen atom, while the nucleophilic sites are around the hydrogen atoms (H20). Normally, the electrophilic ability strengthens and nucleophilic ability weakens. It means that one move outwards from the inner core of the molecule. The title compound has negative chemical potential $(-4.32 \mathrm{eV})$. This infers that it has a weaker tendency to change into the components it is created from and does not decompose. It very well may be delivered intentionally from the components. On the basis of RDG, It confirms H-bond formation between the title molecules. Thus, the present investigation provides a complete and reliable 
structural, spectral and biological activity of the compound. This investigation presents these features of 4-(carboxyamino)-benzoic acid for the first time, but also prepares the ground for future investigations.

\section{REFERENCES}

1. Chang TY, Hu ML, J Nutr Biochem, 1996; 7: 408-413.

2. Basset GJC, Quinlivan EP, Ravanel S, Rebeille F, Nichols BP, et al. Proc Natl Acad Sci USA, 2004; 101: 1496-1501.

3. Pierrel F, Hamelin O, Douki T, Kieffer-Jaquinod S, Muhlenhoff U, et al. Chem Biol, 2010; 17: 449-459.

4. Marbois B, Xie LX, Choi S, Hirano K, Hyman K, et al. J Biol Chem, 2010; 285: 27827-27838.

5. Kluczyk A, Popek T, Kiyota T, de Macedo P, Stefanowicz P, et al. Curr Med Chem, 2002; 9: 1871-1892.

6. Galbinur T, Obolensky A, Berenshtein E, Vinokur V, Chowers I, et al. J Ocul Pharmacol Ther, 2009; 25: 475-482.

7. Akberova SI, Biol Bull, 2002; 29: 390-393.

8. Richards RME, Xing DKL, Int J Pharm, 1995; 116: 217-221.

9. Richards RMR, Xing DKL, King TP, J. Appl Bacteriol, 1995; 78: 209-215.

10. Vasilieva , Mutat Res Genet Toxicol Environ Mutagen, 2001; 496: 89-95.

11. Stroeva OG, Akberova SI, Drozd NN, Makarov VA, Miftakhova NT, et al. Izv Akad Nauk Ser Biol, 1999; 3: 329-336.

12. Drozd NN, Makarov VA, Miftakhova NT, Kalugin SA, Stroeva OG, et al. Eksp Klin Farmakol, 2000; 63: 40-44.

13. Andreenko GV, Karabasova MA, Liutova LA, Podorolskaia LV, Serebriakova TN, et al. Dokl Akad Nauk, 1996; 346: 268-270.

14. Hu Z, Liu J, Shen L, Xu D, Xu Y, J Chem Crystallogr, 2002; 32: 525-529.

15. Xavier S, Macdonald S, Roth J, Caunt M, Akalu A, et al. Int J Radiat Oncol Biol Phys, 2006; 65: 517-527.

16. Hanson KM, Gratton E, Bardeen CJ, Free Radical Biol Med, 2006; 41: 1205-1212.

17. Mackie DS, Mackie LE, Australas J Dermatol, 1999; 40: 51-53.

18. Kostic N, Bozanic M, Vukovic A, Srp Arb Celok Lek, 1992; 120: 269-272. 
19. Lu Z, Kong X, Lu Z, Xiao M, Chen M, et al. Plos One, 2014; 9: e91298.

20. Song GC, Choi HK, Ryu CM, Ann Bot, 2013; 111: 925-934.

21. Bekusarova SA, Bome NA, Weisfeld LI, Tzomatova FT, Luschenko GV, Progress in organic and physical chemistry: Structures and mechanisms. Apple Academic Press; 2013. p. 253-260.

22. Short JH, Ours CW, Ranus WJ, J. Med. Chem., 1968; 11: 1120-1135.

23. Satoh T, Muramatu M, Ooi Y, Miyataka H, Nakajima T, Umeyama M, Chem. Pharm. Bull., 1985; 33: 647-654.

24. Miyamoto Y, Hirose H, Matsuda H, Nakano S, Ohtani M, Kaneko M, Sishigaki K, Nomura F, Kitamura H, Kawashima Y, Trans. Am. Soc. Artif. Int. Organs., 1985; 31: 508-511.

25. Alcolea Palafox M, Nunez JL, Gil M, International Journal of Quantum Chemistry, 2002; 89: 1-24.

26. Wang B, Ma HZ, Inorg. Chem.Commun. 2001; 4: 248.

27. Muthu S, Uma Maheswari J, Spectrochimica Acta Part A: Molecular and Biomolecular Spectroscopy, 2012; 92: 154-163.

28. Bunce S J, Edwards H G, Johnson A F, Lewis I R, and Turner P H, Spectrochimica Acta Part A: Molecular Spectroscopy, 1993; 49: 775-83.

29. Varsanyi G, Vibrational Spectra of Benzene Derivatives, New York: Academic Press, 1969.

30. Kowalczyk I, Journal of Molecular Structure, 2010; 973: 163-172.

31. Machida K, Kagayama A, Saito Y, Kuroda Y, and Uno T, Spectrochimica Acta Part A: Molecular Spectroscopy 33A (1997): 569.

32. Sathyanarayana DN, Vibrational Spectroscopy Theory and Applications, 2nd ed., New Delhi: Age International (P) Limited Publishers, 2004.

33. Ramalingam S, John David EI, Ramachandra Raja C, Jobe Prabakar PC, J Theor Comput Sci., 2014; 1: 2.

34. Govindaswamy Ranganathan Ramkumaar, Shanmugam Srinivasan, Thirumazhisai Jambulingam Bhoopathy, Sethu Gunasekaran, Julie Charles, Jayaprakash Ramesh, Journal of Theoretical and Applied Physics. 2013; 7: 1-14.

35. O’ Boyle NM, Tenderholt AL, Langer KM, J. Comput. Chem., 2008; 29: 839-845. 
36. Renuga S, Karthikesan M, Muthu S, Spectrochimica Acta Part A: Molecular and Biomolecular Spectroscopy., 2014; 127: 439.

37. Halil Gökce, Semiha Bahçeli, Spectrochimica Acta Part A: Molecular and Biomolecular Spectroscopy, 2012; 96: 139-147.

38. S.N.Saravanamoorthy, M.Banu, R.Rachel Joy, Ad. J. Chem. B, 2021; 3: 120-147.

39. Sundaraganesan N, Maganathan C, Dominic Joshua N, Mani P, Jayaprakash P, Spectrochim. Acta Part A, 2008; 71: 1134-1139.

40. Govindasamy P, Gunasekaran S, Srinivasan S, Spectrochimica Acta Part A: Molecular and Biomolecular Spectroscopy, 2014; 130: 329-336.

41. Agarwal P, Choudhary N, Gupta A, Tandon P, Vib. Spectrosc., 2013; 134: 64.

42. Alparone A, Adv. Phys. Chem., 2013; 1: 2013.

43. Anuj kumar, Mahesh Pal Singh Yadav, Pramana -J. Phys., 2017; 89: 7.

44. Fleming I, Frontier Orbitals and Organic Chemical Reactions, John Wiley \& Sons, New York, 1978.

45. Parr RG, Pearson RG, J. Am. Chem. Soc., 1983; 105: 7512-7516.

46. Parr RG, Yang W, Functional Theory of Atoms and Molecules, Oxford University Press, New York, 1989.

47. Inkaya E, J Mol Struct., 2018; 1173: 148-156.

48. Bakkiyaraj D, Periandy S, Xavier S, J Mol Struct. 2016; 1108: 33-45.

49. Arshad MN, Bibi A, Mahmood T, Molecules, 2015; 20: 5851-5874.

50. Rajalakshmi K, Gunasekaran S, Kumaresan S, Indian J Phys., 2015; 89: 525-538.

51. Reed AE, Weinstock RB, Weinhold F, J. Chem.Phys., 1985; 83: 735-746.

52. Govindarajan M, Karabacak M, Spectrochim. Acta Part A, 2012; 96: 421-435.

53. Yadav T, Sahu R K, Mukherjee V, J. Mol. Struct., 2019; 1176: 94-109.

54. Sevvanthi S, Muthu S, Raja M, J. Mol. Struct., 2018; 1173: 251-260.

55. Veeraragavan Vijayakumar, Arunachalam Prabakaran, Narayanaswamy Radhakrishnan, Sambanthan Muthu, E. Isac Paulraj, J. Mol. Struct., 2019; 1179: $325-$ 335.

56. Noureddine O, Issaoui N, Medimagh M, Al-Dossary O, Marouani H, Journal of Kind Saud University - Science, 2021; 33(2): 101334.

57. Schlick T, Molecular Modeling and Simulation: An Interdisciplinary Guide, 2nd ed. Springer, New York, 2010, p. $20 \& 243$.

58. Marinescu M, Emandi A, Marton G, Cinteza LO, Constantinescu C, Nanoscience and Nanotechnology Letters, 2015; 7: 1-9. 
59. Wazzan N, Safi Z, Journal of Molecular Structure., 2017; 1143: 397-404.

60. Lipinski C A, Lombardo F, Dominy B W, Feeney P J, Adv. Drug Deliv. Rev., 1997; 23: $3-25$.

61. Govindammal M, Prasath M, Heliyon, 2020; 6: e04641.

62. Singh S, Singh J, Med. Res. Rev., 1993; 13: 569-621.

63. Zhao Y H, Le J, Abraham M H, Hersey A, Eddershaw P J, Luscombe C N, J. Pharm. Sci., 2001; 90: 749-784.

64. Alavijeh M S, Christy M, Qaiser M Z, NeuroRx2, 2005; 2005: 554-571.

65. Ying Han, Jingpu Zhang, Chang Qin Hu, Xia Zhang, Bufang Ma, Front. Pharmacol, 2019; 10: 434.

66. Pires D E, Blundell T L, Ascher D B, J.Med.Chem., 2005; 58: 4066-4072.

67. Tristani-Firouzi M, Chen J, Mitcheson J S, Sanguinetti M C, Am. J. Med., 2001; 110: 50-59.

68. Hsu KC, Chen YF, Lin SR, Yang JM, BMC Bioinformatics, 2011; 12: 1-11. 